\title{
Arctic climate response to forcing from light-absorbing particles in snow and sea ice in CESM
}

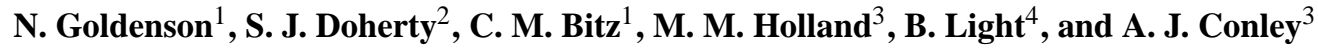 \\ ${ }^{1}$ Department of Atmospheric Sciences, P.O. Box 351640, University of Washington, Seattle, WA 98195, USA \\ ${ }^{2}$ Joint Institute for the Study of Atmosphere and Ocean, 3737 Brooklyn Ave NE, Seattle, WA 98195, USA \\ ${ }^{3}$ National Center for Atmospheric Research, P.O. Box 3000, Boulder, CO 80307, USA \\ ${ }^{4}$ Applied Physics Laboratory, Polar Science Center, Box 355640, University of Washington, Seattle, WA 98105, USA
}

Correspondence to: N. Goldenson (ngoldens@uw.edu)

Received: 31 December 2011 - Published in Atmos. Chem. Phys. Discuss.: 20 February 2012

Revised: 7 July 2012 - Accepted: 11 August 2012 - Published: 5 September 2012

\begin{abstract}
The presence of light-absorbing aerosol particles deposited on arctic snow and sea ice influences the surface albedo, causing greater shortwave absorption, warming, and loss of snow and sea ice, lowering the albedo further. The Community Earth System Model version 1 (CESM1) now includes the radiative effects of light-absorbing particles in snow on land and sea ice and in sea ice itself. We investigate the model response to the deposition of black carbon and dust to both snow and sea ice. For these purposes we employ a slab ocean version of CESM1, using the Community Atmosphere Model version 4 (CAM4), run to equilibrium for year 2000 levels of $\mathrm{CO}_{2}$ and fixed aerosol deposition. We construct experiments with and without aerosol deposition, with dust or black carbon deposition alone, and with varying quantities of black carbon and dust to approximate year 1850 and 2000 deposition fluxes. The year 2000 deposition fluxes of both dust and black carbon cause $1-2{ }^{\circ} \mathrm{C}$ of surface warming over large areas of the Arctic Ocean and subArctic seas in autumn and winter and in patches of Northern land in every season. Atmospheric circulation changes are a key component of the surface-warming pattern. Arctic sea ice thins by on average about $30 \mathrm{~cm}$. Simulations with year 1850 aerosol deposition are not substantially different from those with year 2000 deposition, given constant levels of $\mathrm{CO}_{2}$. The climatic impact of particulate impurities deposited over land exceeds that of particles deposited over sea ice. Even the surface warming over the sea ice and sea ice thinning depends more upon light-absorbing particles deposited over land. For $\mathrm{CO}_{2}$ doubled relative to year 2000 levels, the climate impact of particulate impurities in snow and sea ice is substantially lower than for the year 2000 equilibrium simulation.
\end{abstract}

\section{Introduction}

Pollutants emitted in mid-latitudes are transported to the Arctic, where they can influence Arctic regional climate and air quality (Shindell et al., 2008). These pollutants originate from mid-latitude population centers burning fossil fuels as well as from biomass burning, products of which can be transported to the Arctic from forest and agricultural fires on large scales (Warneke et al., 2009). Regional climate in the Arctic in turn affects global climate. Thus pollutants have impacts on multiple scales simultaneously: the immediate local effects on health and the environment, and the longer-range effects that may have global impact.

Arctic aerosol particles interact with multiple processes and components of the climate system. Small particles have an indirect impact via their effect on clouds, providing cloud condensation nuclei, and changing the quantity or the reflective properties of clouds, and they have a direct impact in the form of light scattering and absorption by atmospheric Arctic haze (Law and Stohl, 2007; Quinn et al., 2007). Particulate pollutants are deposited to the surface and incorporated in snow and sea ice in the Arctic.

Black carbon (BC), due to its light-absorbing properties, may alter the reflectivity of the surface snow and ice sufficiently to alter the energy budget of the region (Clarke and Noone, 1985; Warren and Wiscombe, 1985; Hansen and Nazarenko, 2004). Additionally, the impurities found in Arctic snow and sea ice are not limited to black carbon, and some of these impurities also absorb light and lower snow and ice albedo. Soil dust particles can also be transported globally through the atmosphere (Mahowald et al., 2010), depositing in the Arctic as well. 
Many aerosol processes have only recently been incorporated into climate models, and they need further evaluation and testing. Flanner et al. (2007) presented a model study of the climate effects of black carbon in snow, using a snow radiation scheme which they incorporated into an earlier version of the model that we use, which is the Community Earth System Model version 1 (CESM1). In the studies of Flanner et al. $(2007,2009)$ the effects of BC and dust in snow on motionless sea ice were included, but the effects of particulate impurities in the ice itself were not accounted for. More recently Holland et al. (2012) showed the impact of incorporating particle transport and optical effects into a sophisticated dynamic sea ice model. Holland et al. (2012) investigated the response to varying particles in sea ice and snow on sea ice but not in terrestrial snow, whereas Lawrence et al. (2012) include evaluation of only the role of particulate in terrestrial snow in CESM1.

To correctly estimate the forcing from particulate impurities in snow and sea ice, other processes, including haze formation and particle transport, the atmospheric boundary layer dynamics, and clouds must not be grossly misrepresented. Studying these processes individually is useful because they do not always have effects that add linearly. Other work on surface particulate impurities, for which aerosols might be interactively generated rather than prescribed, would capture additional feedbacks in the climate system. Thus it is useful to study the impact of the surface particulate forcing in isolation, just as we study each of these processes individually to inform our interpretation of model simulations in which all are parameterized at once.

We explore the sensitivity of the CESM to the incorporation of particulate impurities in Arctic snow and sea ice, using constant deposition fluxes and prescribed atmospheric aerosols in slab ocean equilibrium simulations. Thus we isolate one interface at which light-absorbing particles interact with the climate system, to better understand what can be expected from model simulations of feedbacks and interactions that include this component.

\section{Background}

\subsection{Importance of snow and ice optics}

The components of the Earth surface that are most affected by darkening impurities are high albedo surfaces. As shown in Warren and Clarke (1986), the amount of an impurity, such as $\mathrm{BC}$, required to substantially affect the albedo of snow, may not be obvious to the eye. The measurements of $\mathrm{BC}$ concentration in snow or sea ice that have been made (e.g., Doherty et al., 2010) help us to constrain the potential magnitude of impact of $\mathrm{BC}$ on climate.

The snow albedo feedback refers to the process by which surface warming melts snow, lowering the surface albedo by wetting the snow or revealing a darker underlying surface, which in turn leads to more solar energy absorption, warming the surface further, and resulting in additional snow melt. The feedback that occurs when sea ice melts is analogous.

There are additional fine-scale feedbacks within the snow deposits that amplify the impact of impurities on the overall snow albedo. The albedo of snow changes with aging, with or without the presence of light-absorbing impurities. As snow ages, grain size increases and albedo is reduced (Wiscombe and Warren, 1980). The presence of impurities accelerates snow aging by additionally lowering the albedo (Warren and Wiscombe, 1980), leading to more absorption and a warmer surface. A warmer surface leads to faster snow aging, which lowers the albedo even further (Flanner and Zender, 2006), eventually leading to earlier melt. Measurements indicate that a fraction of the $\mathrm{BC}$ is left at the snow surface with melt (rather than washing away), further lowering surface snow albedo and accelerating melt (Conway et al., 1996; Xu et al., 2006; Doherty et al., 2010).

\subsubsection{Land surface model}

These snow aging and grain size processes, and melt consolidation of BC, are represented in the Snow, Ice, and Aerosol Radiative (SNICAR) model (Flanner and Zender, 2005), which is used in the Community Land Model version 4 (CLM4), in CESM1. Although all of the same processes occur in nature in snow on top of sea ice, the sea ice model in CESM1 is more simplistic in its representation of the snow pack, due to constraints of computational efficiency (see Sect. 2.1.2).

Snow processes that affect albedo, including melt, metamorphism, deposition and redistribution, are patchy on a scale much smaller than a grid cell. Thus, a snow cover fraction parameterization is included in CLM4 (Niu and Yang, 2007), which is an improvement over the previous version. Other parameterizations, which have been updated for CLM4, are required for snow compaction (Lawrence and Slater, 2010) and calculating albedos where snow falls on or around vegetation (Wang and Zeng, 2009).

The overall snow treatment in CLM4 is described in Lawrence et al. (2011). Snow processes are of ultimate importance to the accurate representation of surface albedo, which compares well to observations from AVHRR according to Lawrence et al. (2012). Compared to the previous model version, the albedo contrast between snow-covered and non-snow-covered area is more consistent with observations, as is the albedo of snow itself, leading to a lower magnitude of surface albedo feedback (Lawrence et al., 2012).

The impact of changed representations of processes involving snow is better seen in the present climate. Simulations of future climates show that the greenhouse gas warming within a century overwhelms the signal of snow-related processes on soil temperature (Lawrence and Slater, 2010) and other surface conditions. 


\subsubsection{Sea ice model}

For the sea ice component of CESM1, the base code comes from the Los Alamos National Laboratory Sea Ice Model version 4 (CICE4; Hunke and Lipscomb, 2008). Ice is dynamically deformed and transported in response to winds and ocean currents, so all of the properties of a given unit of ice must be transported in the model. These properties include all tracers for particulate impurities, in both the ice itself as well as the snow on sea ice.

Transporting a large number of snow and ice particulate impurity tracers in the sea ice model is computationally expensive compared to the land model where modeled snow is immobile. As a result, only a minimal number of opticallyactive layers are included in the sea ice model, and the number of particle sizes is fewer. The number of wavelengths considered for light-absorbing particles is also fewer than in the land snow model.

Briegleb and Light (2007) explain in detail the radiative transfer scheme in CICE4. The albedo is determined by radiative transfer through the top layers of ice, and snow if it is present. There are two optically-active layers of snow on sea ice, in which light-absorbing particles can influence optics. The top two layers of the sea ice itself have in-ice optics influenced by light-absorbing particles.

While most sea ice is covered by snow for much of the year, in the spring and early summer when solar downwelling radiation is at its maximum, there is substantial ice exposed. That is why in-ice optics in the presence of particulate impurities are also taken into account. CESM includes explicit ice optics (Briegleb and Light, 2007; Holland et al., 2012), which allows us to experiment with light-absorbing particles in the sea ice model.

\subsection{Constraints on particle parameters}

The way that light-absorbing particles interact with radiation, whether suspended in the atmosphere or the cryosphere, depends on their size and composition, and the wavelength of radiation under consideration. The greater the number of distinct sizes, wavelengths, and variations in particle optical properties that are represented, the more potentially accurate the simulation. As with all large-scale climate model simulations, the radiation treatment is an approximation meant to balance accuracy with computational efficiency. We will outline the particular particle properties and wavebands used in the snow and sea ice components of CESM.

The optical properties of both black carbon and dust used in the model are the same for particles deposited on sea ice and terrestrial snow. The BC particles consist of a hydrophobic and a hydrophilic component. The hydrophobic BC optical properties come from Chang and Charalampopoulos (1990). As described by Flanner et al. (2007), a lognormal size distribution is assumed and density adjusted to ensure a $550 \mathrm{~nm}$ mass absorption cross-section (MAC) of
$7.5 \pm 1.2 \mathrm{~m}^{2} \mathrm{~g}^{-} 1$, the value recommended by Bond et al. (2006). This MAC is intended for freshly emitted industrial BC (see Bond and Bergstrom, 2006).

The hydrophilic black carbon optics are based on the hydrophobic properties, with the addition of a sulfate coating (Flanner et al., 2007) that alters the optical properties as per Mie theory of particle scattering and absorption, yielding an absorption enhancement of $\sim 1.5$ as suggested by Bond et al. (2006). As discussed in Flanner et al. (2012), BC internallymixed with an ice coating - which is absent from this and other prior studies with this model - can enhance absorption, but sulphate coatings behave in a similar way to ice-coatings, so overall MAC may not be grossly under-represented. Unfortunately the frequency of distinct mixing states of $\mathrm{BC}$ in snow is not known.

Sometimes references to the products of incomplete combustion distinguish "brown" carbon or "organic" carbon from black carbon to emphasize a distinction in particle composition. Flanner et al. (2007) find that accounting for light absorption by brown carbon/organic carbon in the snow does not substantively change their results compared to simulations that only account for absorption by black carbon. We follow that precedent in our simulations, using what have become the CESM default optical properties, as described below.

Dust optical properties are based on Patterson (1981), as explained in Zender et al. (2003). These dust optical properties, applied globally, are based on measurements of Saharan dust, which may differ from the optical properties of dust from other source regions (Sokolik and Toon, 1999). Accounting for the differences in the optical properties of dusts from different regions may prove another interesting topic for future modeling studies, when better observational constraints and computational resources are available.

In the SNICAR snow treatment, there are five spectral bands: $0.3-0.7 \mu \mathrm{m}, 0.7-1.0 \mu \mathrm{m}, 1.0-1.2 \mu \mathrm{m}, 1.2-1.5 \mu \mathrm{m}$, and 1.5-5.0 $\mu \mathrm{m}$. (Flanner et al., 2007). The types of lightabsorbing particles considered are BC (hydrophilic and hydrophobic) and dust. For the dust there are four size bins: $0.1-1.0 \mu \mathrm{m}, 1.0-2.5 \mu \mathrm{m}, 2.5-5.0 \mu \mathrm{m}$, and 5.0-10.0 $\mu \mathrm{m}$ (Mahowald et al., 2006), representing the range relevant for interaction with solar radiation.

In the CICE4 there are only three spectral bands: 0.3$0.7 \mu \mathrm{m}, 0.7-1.19 \mu \mathrm{m}$, and $1.19-5.0 \mu \mathrm{m}$. The types of particles represented are BC (hydrophilic and hydrophobic) and dust. Distinct sizes of dust are not represented. Although the model is set up to allow up to four dust particle size bins, as in SNICAR, only one is in use by default and in this study. The use of fewer wavebands in the CICE model compared to the land model, like the use of fewer dust particle sizes, is a choice driven by computational constraints.

The optical properties for black carbon (Chang and Charalampopoulos, 1990) used in CESM1 derive from laboratory measurements of freshly-emitted flame-generated soot. Although organic carbon is co-emitted with black carbon, 
Table 1. Global annual mean two meter temperature change, $\Delta T$, change in net TOA shortwave radiation, $\Delta Q_{\mathrm{SW}}$, and radiative forcing, $\Delta F$. See Sect. 4.1.1 for a detailed description of $\Delta F$.

\begin{tabular}{lcccl}
\hline & $\Delta T\left({ }^{\circ} \mathrm{C}\right)$ & $\Delta Q_{\mathrm{SW}}\left(\mathrm{W} \mathrm{m}^{-2}\right)$ & $\Delta F\left(\mathrm{~W} \mathrm{~m}^{-2}\right)$ & particulate in sea ice? \\
\hline all surface particulate (BC and dust) & 0.17 & 0.20 & 0.059 & yes \\
BC only on sea ice and land & 0.11 & 0.17 & 0.039 & yes \\
dust only on sea ice and land & 0.12 & 0.17 & 0.037 & yes \\
BC and dust on land but not sea ice & 0.14 & 0.24 & - & no \\
Flanner et al., 2009 (BC only) & 0.07 & - & 0.057 & only snow on sea ice \\
Jacobson, 2004 (BC only) & 0.20 & - & - & yes \\
\hline
\end{tabular}

absorption by organic carbon is not included in snow and sea ice in the model. Despite this omission, it is possible that "brown carbon" in fact plays a significant role in Arctic snow and ice light absorption. Using an Arctic-wide set of snow and sea ice samples, Doherty et al. (2010) found that typically $\sim 20-40 \%$ of particulate light absorption is due to constituents other than BC, and Hegg et al. (2009, 2010), through a chemical source attribution, show that most of the particulate light absorption in those same samples is from biomass or biofuel burning, not industrial sources or mineral dust. This is consistent with Stohl (2006), who found a large portion of modeled BC transport from fires as opposed to industrial sources. In general, biomass combustion aerosol has a much higher fraction of light-absorbing organic carbon (relative to BC) than does fossil fuel combustion (Bond et al., 2004), so it is very likely that the non-BC absorption reported by Doherty et al. (2010) is from organics. If the non-BC particle fraction is significantly absorbing due to greater mass or greater absorption efficiency than that which has been assumed, then the net absorption from combustion sources may be underestimated. While we focus here on the current formulation of CESM, future studies should revisit organic/brown carbon contributions to light absorption in snow and sea ice.

\subsection{Previous studies and gaps}

Other studies have used models to help constrain the magnitude of the forcing from black carbon specifically, or lightabsorbing particles generally, on snow and sea ice. However, this is the first study with CESM1 (or its predecessors) to compare the forcing by both BC and dust on land snow, snow on sea ice, and in sea ice itself, isolating the climate effects of forcing by impurities in terrestrial snow versus in sea ice.

Hansen and Nazarenko (2004) drew attention to forcing by $\mathrm{BC}$ on snow and sea ice by suggesting an instantaneous radiative forcing of $+0.3 \mathrm{~W} \mathrm{~m}^{-2}$ for the Northern Hemisphere (where most BC is deposited). Their model, the Goddard Institute for Space Studies climate model, did not have the type of detailed snow or sea ice radiation treatment currently found in CESM1. Instead albedo changes due to BC were prescribed, fixed values over broad geographic areas, based on few observed values of Arctic snow BC concentrations.
Rather than focus exclusively on the surface forcing (via the albedo effect in snow and ice), Jacobson (2004) looked at the impact of BC on climate, including forcing by both atmospheric and surface-deposited particles, using the Gas, Aerosol, Transport, Radiation, General Circulation, Mesoscale, and Ocean Model (GATOR-GCMOM). This model does not contain snow and sea ice representations as complex as CESM1: there is one radiatively active layer in snow or sea ice at the surface, and feedbacks to snow properties (grain size, etc.) are not included. The impact on surface temperature calculated by Jacobson due to BC in snow and sea ice is smaller than in Hansen and Nazarenko (2004), although Jacobson calculates a greater temperature response due to BC in the atmosphere as well as in snow and sea ice.

Unlike GATOR, which calculates deposition fluxes interactively with the model's atmospheric aerosol treatment, the CESM simulations presented here will prescribe deposition rates in equilibrium simulations. This way we can change the surface forcing independent of prognostic variation in the atmospheric aerosol forcing, since atmospheric aerosols are held constant in our simulations. The radiative forcing and climate response of Jacobson (2004) and other studies described in this section are summarized in Table 1 along with the results from our integrations for ease of comparison.

Others have evaluated model representation of lightabsorbing particles in CESM1, in one model component or another. When SNICAR was first incorporated into a predecessor of CESM1, forcing by BC in snow on sea ice was included, but particles on bare ice were not included. Thus the climate response predicted in Flanner et al. (2007, 2009) does not include the full impact of light-absorbing particles on sea ice.

Flanner et al. (2007) conducted sensitivity studies of the effect on forcing of varying modeled BC MAC, wash-out rate of BC with melt, snow cover, and the treatment of snow aging rate (grain size effects). While we reproduce some climaterelevant sensitivity studies below, we should point out that there remains uncertainty about some of the characterization of BC or dust in-snow processes, as given by Flanner et al.'s analysis (their Table 4). Although we did not repeat all of their sensitivity experiments, we varied BC MAC as in Flanner et al. (2007) by plus or minus a standard deviation (as 

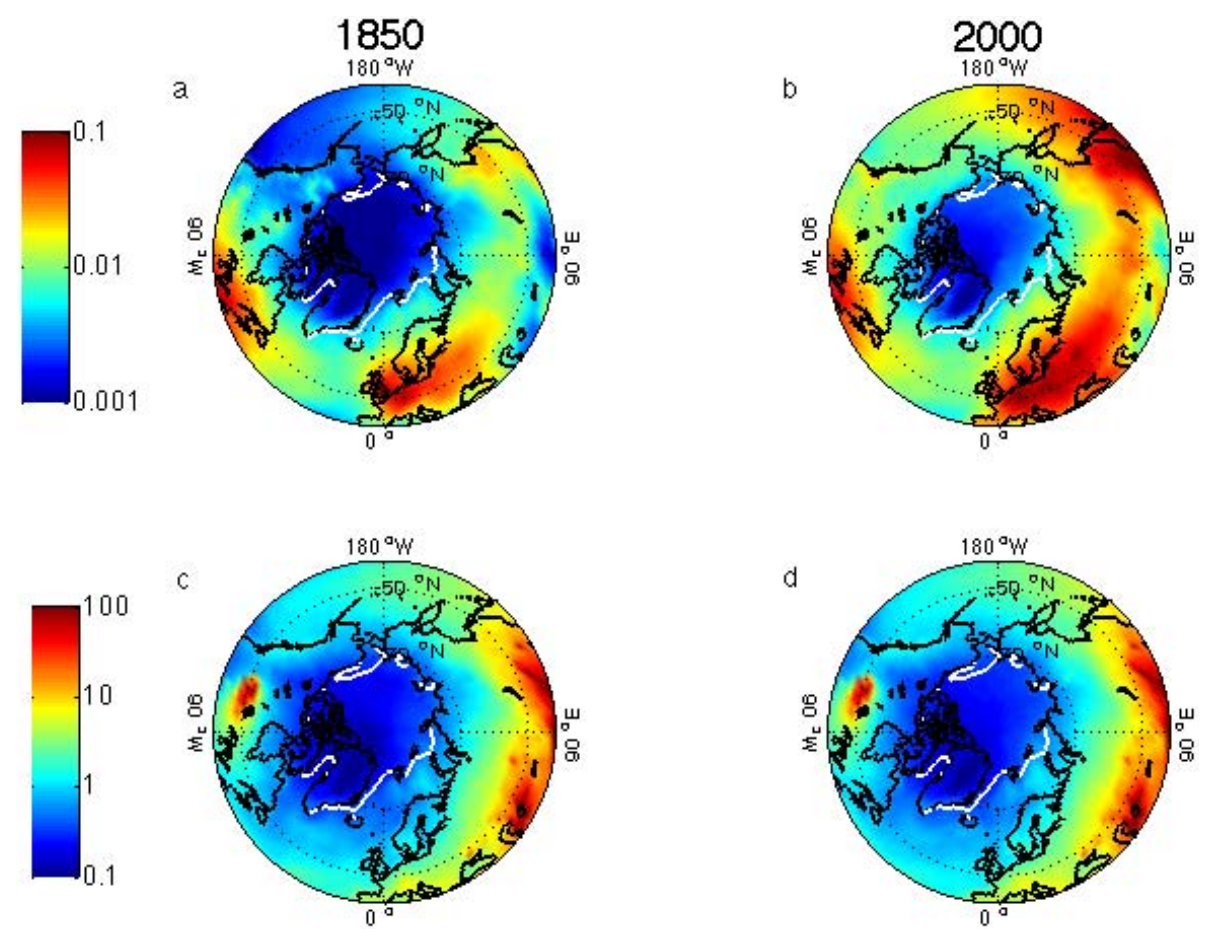

Fig. 1. Prescribed black carbon year 1850 (a) and year 2000 (b) deposition fluxes $\left(\mathrm{g} \mathrm{m}^{-2} \mathrm{yr}^{-1}\right)$ annual average, demonstrate the much smaller quantities of aerosol deposited on sea ice compared to land snow. The white line shows September sea ice $15 \%$ ice area contour for reference from one of our simulations without aerosol deposition. (c) and (d) show the same for dust deposition fluxes.

calculated from the set of laboratory measurements that Bond and Bergstrom (2006) average to obtain their recommended MAC value), and found no significant equilibrium temperature response. Thus, we use the optical properties as specified in previous CESM1 studies with some confidence that, at least for BC, any errors within one standard deviation do not substantially bias the climate response.

Lawrence et al. (2012) investigated the relative importance of $\mathrm{BC}$ and dust deposition on terrestrial snow only (not on sea ice or snow on sea ice) in the CESM1. They found that forcing from dust in snow is about equal to that of $\mathrm{BC}$ in snow. They note that Flanner et al. (2009) found a relatively higher forcing from $\mathrm{BC}$ than from dust in snow, and that the change can be mostly attributed to updates in emission scenarios that predict more dust.

The study of Holland et al. (2012) is the complement of Lawrence et al. (2012). They explore the effects of lightabsorbing deposition on sea ice and snow on sea ice alone (not on terrestrial snow) in the CESM1. No study has yet investigated the role of light-absorbing particles in terrestrial and sea ice components together in CESM1. Here we compare their impact across components and for dust and $\mathrm{BC}$ independently.

\section{Methods}

\subsection{Model experiment design}

For our study we use CESM1 with a slab ocean and the full dynamic/thermodynamic sea ice component, both at one degree resolution. The atmosphere component is the Community Atmosphere Model 4 (CAM4) at two degree resolution. Ocean heat flux is prescribed based on the climatology of a long pre-industrial control integration. This particular model configuration is described more fully in Bitz et al. (2012). All of the results presented are for at least 60 -yr equilibrium simulations, for which the last $30 \mathrm{yr}$ have been averaged to create a climatology. Carbon dioxide is fixed at year 2000 levels.

In all of our simulations we use seasonally repeating deposition fluxes for aerosols from the atmosphere, rather than a deposition flux that depends on the model-simulated atmosphere. These deposition fluxes themselves come from a separate model simulation (Lamarque et al., 2010) and can only be roughly constrained by observations (see Sect. 3.2) due to the limited spatial and temporal distribution of concentration measurements in the Arctic. See Fig. 1 for the annual average deposition of $\mathrm{BC}$ and dust that is prescribed. Most of our simulations use year 2000 levels (Fig. 1b and d). The seasonal variation of $\mathrm{BC}$ and dust deposition fluxes can be seen in Fig. 2. 


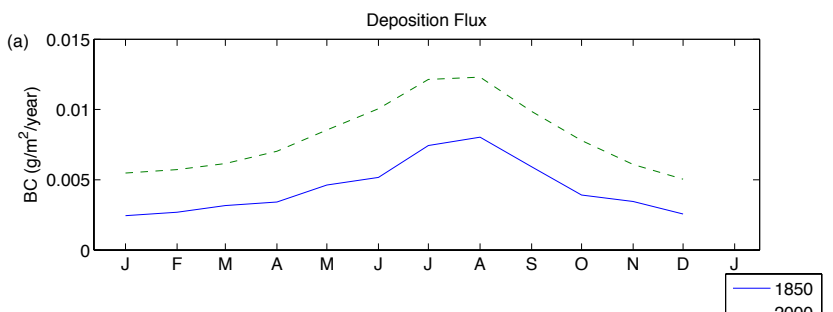

(b)

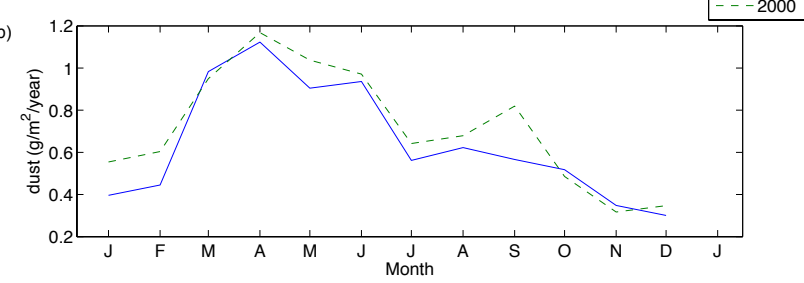

Fig. 2. Prescribed black carbon (a) and dust (b) year 1850 and year 2000 deposition fluxes $\left(\mathrm{g} \mathrm{m}^{-2} \mathrm{yr}^{-1}\right)$ as a function of month for latitudes North of $60^{\circ} \mathrm{N}$.

Seasonally varying atmospheric aerosols are also prescribed in these simulations, rather than generated by the model. Holding constant atmospheric aerosols allows us to isolate the impact of surface particulate forcing in this study.

We focus on the Arctic because that is a region with substantial areas of high-albedo snow and sea ice where particulate deposition is also present. Most aerosol emissions are from the Northern Hemisphere where most of the land mass and population is located, and cross-hemispheric transport is limited by atmospheric circulation patterns. The lightabsorbing surface particulate forcing is small in Antarctica compared to the Northern Hemisphere in observations (Warren and Clarke, 1990) and in CLM4 (Lawrence et al., 2012). Thus, we do not evaluate the Southern polar region in this study.

While mountain glaciers are important for a number of reasons (local water supplies not least), their small area means that they do not have the potential to be involved in the same large-scale albedo feedbacks as are possible in the large area of the Arctic basin, nor is a coarse-resolution climate model capable of resolving catchment-scale processes. In contrast, surface temperature and the state of terrestrial snow and sea ice in the Arctic are well-simulated by CESM (Jahn et al., 2012). The ice sheets on Greenland and Antarctica are always covered by snow, so the land snow treatment suffices.

\subsection{Validation of concentrations}

We compare observations of black carbon concentration in sea ice measured in field campaigns (Doherty et al., 2010) to our modeled values to see whether the model approximates these quantities appropriately. Model concentrations in sea ice are a function of the deposition fluxes (Lamarque et al., 2010), but also of the sea ice dynamics, and other redistribu-

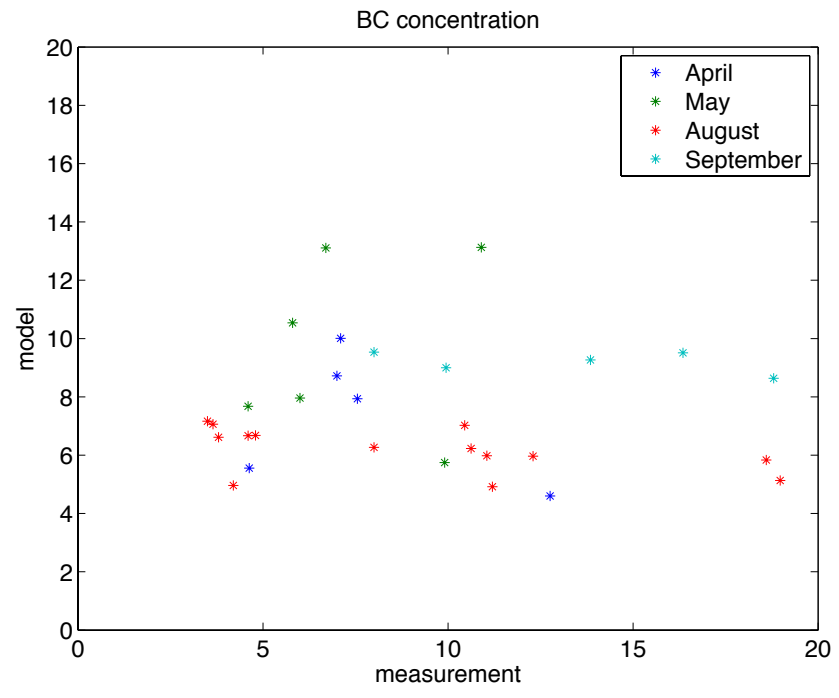

Fig. 3. Model and observed BC concentrations ( $\left.\mathrm{ng} \mathrm{g}^{-1}\right)$ in the top, surface scattering layer of sea ice or snow on sea ice are compared. Each point represents an average of observations compared with a climatological value for the model grid box that contains those latitude-longitude locations.

tion of $\mathrm{BC}$ in the snow/ice as particles accumulate or wash out when melting occurs.

As seen in Fig. 3, the modeled concentrations in a given grid box, fall in the same range as observations made at a location within that grid box. Depths of measurements in Fig. 3 and Fig. 4 come from no deeper than the top $5 \mathrm{~cm}$ of a sample. In the model, the values being compared are for the top layer. In the sea ice model this is the surface scattering layer (SSL) described in Holland et al. (2012) and is $4 \mathrm{~cm}$ or $5 \mathrm{~cm}$ for thick snow and sea ice respectively. The SSL is adjusted to be half the snow thickness for thin snow and 1/30th the ice thickness for thinner ice. In CLM the top snow layer is $2 \mathrm{~cm}$ (Flanner and Zender, 2005).

It should be noted that most of the sea ice model variability is temporal, with higher concentrations as time progresses from early spring to fall. The same tendency is not seen in the observations. In the model, BC accumulates throughout the melt season, whereas observed concentrations are more spatially variable, and the range of concentrations does not systematically change with season. Compared to the data for particles in sea ice or snow on sea ice, measurements in land snow tend to have lower concentrations than that of the climatological modeled values, by about a factor of two. Year to year variability could explain deviations of this magnitude. McConnell et al. (2007) document anomalous years with black carbon concentrations in Greenland snow that are a factor of ten above the norm even during pre-industrial time, using a Greenland ice core.

The observational range is greater, but that is to be expected because the data points represent individual observations, whereas the model points are part of a climatological 


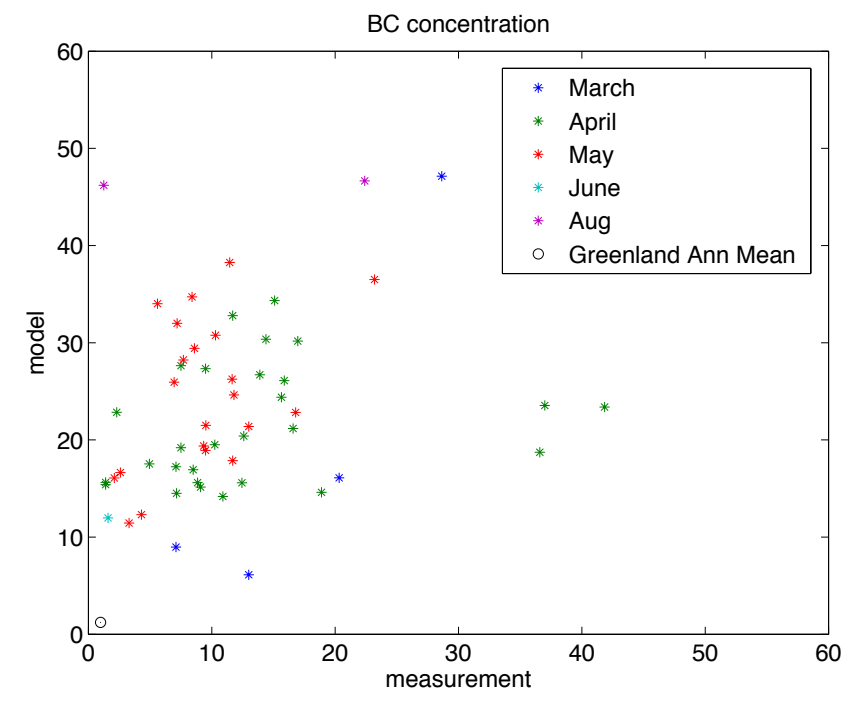

Fig. 4. Model and observed BC concentrations $\left(\operatorname{ng~g}^{-1}\right)$ in the top snow layer on land are compared. Each point represents an average of observations compared with a climatological value for the model grid box that contains those latitude-longitude locations. For comparison, an annual mean value for the year 2000 from the ice core described in McConnell et al. (2007) is also plotted against model climatology.

average taken over a larger scale (grid box size of one degree latitude/longitude). There does not exist the degree of temporal and spatial resolution in measurements on either land or sea ice to verify whether locally appropriate concentrations are being prescribed throughout the Arctic basin at all times of year. However, all of the modeled values are within the range of the observed concentrations. We can proceed to evaluate model sensitivity and climate impacts with a general understanding of model biases in snow BC concentrations.

\section{Results and discussion}

\subsection{Surface particulate impurity forcing}

In this section we present results that isolate the climate response of the model to forcing from black carbon and dust in terrestrial snow as well as sea ice and snow on sea ice.

\subsubsection{Global climate response}

First we compare equilibrium simulations with and without light-absorbing particulates included in snow and sea ice, leaving prescribed atmospheric aerosols constant, and carbon dioxide levels at a constant year 2000 value. The global annual top of atmosphere (TOA) radiative forcing for BC and dust combined is $\Delta F=0.06 \mathrm{~W} \mathrm{~m}^{-2}$. This estimate of radiative forcing is solely due to the change in shortwave absorption, and it is computed by running the radiative transfer scheme twice, with and without the changes to albedo due to surface particulates in the snow and sea ice. We note that the climate state of the model when this calculation is performed is that of a climate in which particulate impurities have been present. Thus the snow pack, even without impurities directly affecting its albedo, would be altered by their presence.

Because the radiative transfer scheme is run both times with the same temperature profile, we refer to our estimate as an "instantaneous" radiative forcing. However, our use of this term is slightly different from the IPCC AR4 (Fig. 2.2, IPCC, 2007) because the temperature profile in our case is fully adjusted and the flux imbalance is taken at the top of atmosphere. Because the stratosphere adjusts very little to surface impurities, we argue that our instantaneous radiative imbalance is very nearly equal the stratospheric-adjusted radiative imbalance at the tropopause.

The global annual mean change in TOA net shortwave radiation between equilibrium climate integrations with and without surface impurities is $\Delta Q_{\mathrm{SW}}=0.20 \mathrm{~W} \mathrm{~m}^{-2}$. This measure of the shortwave radiative response, when compared to the forcing, reflects the role of feedbacks in the system. The global-mean, annual two-meter air temperature response is $\Delta T=0.17 \pm 0.07^{\circ} \mathrm{C}$ (the uncertainty estimate is from a $210 \mathrm{yr}$ long integration and applies to all of our estimates for $\Delta T)$.

Next we turn to the regional distributions of the quantities. In Sect. 4.3 we return to these global estimates as we summarize our findings for $\Delta F, \Delta Q_{\mathrm{SW}}$, and $\Delta T$ from all of our simulations and compare them to previous studies (also see Table 1), including estimates of efficacy of the forcing from light-absorbing particles in snow and sea ice compared to the forcing from $\mathrm{CO}_{2}$.

\subsubsection{Arctic climate response}

Light-absorbing particulate radiative forcing $(\Delta F)$ varies in space and in season (Fig. 5). As previously noted (Flanner et al., 2009), the magnitude of surface particulate impurity radiative forcing is greatest in the Northern Hemisphere spring. The radiative forcing is due primarily to changes in surface albedo over land. Figure 6 shows the seasonal cycle of overall surface albedo on land for latitudes greater than $60^{\circ} \mathrm{N}$. In the fall the difference in land surface albedo, with and without the surface light-absorbing particulate, is negligible, whereas it is larger in the other months.

Snow melt rate peaks earlier in the integration that includes impurities (Fig. 7). The impact of light-absorbing particles in land snow can be seen in the difference maps of snow thickness (liquid water equivalent), and the maps of surface albedo change. Snow thickness differences between the runs with and without aerosol deposition (Fig. 8a-d) are somewhat variable in the spring, but by June the case that includes aerosol deposition has systematically less snow in large areas with significant differences. Even when snow is deeper in the integration with particulate impurities, the particles may still darken the snow, so snow thickness and albedo differences 

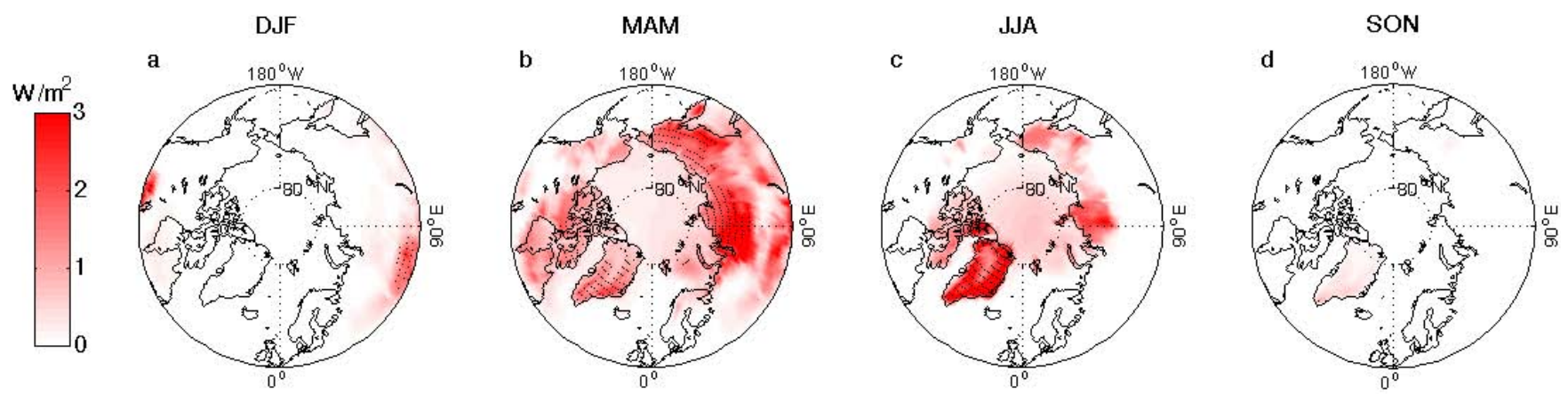

Fig. 5. Radiative forcing, $\Delta F$, in $\mathrm{W} \mathrm{m}^{-2}$, for each season due to light-absorbing particles in snow and sea ice. Carbon dioxide is constant at a year 2000 level. Hashes indicate where differences are significant to $95 \%$ confidence in this and other figures where they appear.

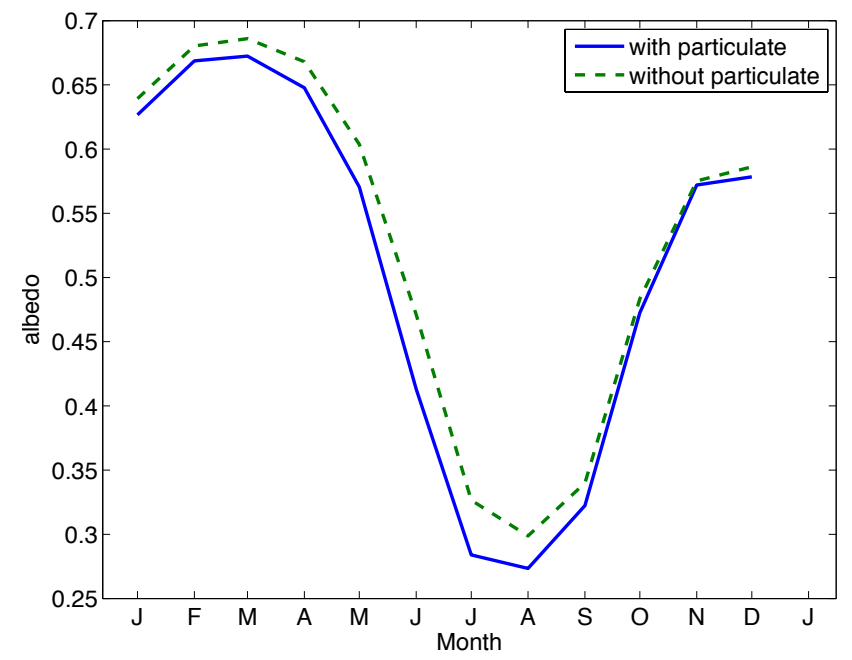

Fig. 6. The seasonal cycle of overall land surface albedo North of $60^{\circ} \mathrm{N}$, both with and without the surface particulate impurity forcing applied. Note that the difference between the two varies with the time of year.

do not necessarily correlate. The impact on surface albedo is shown for same months in Fig. 8e-h. Later in the spring, the albedo contrast is between the snow and the ground beneath, and so quantity of snow correlates better with the overall albedo difference.

The role of the snow and sea ice albedo feedback is evident in the maps of $\Delta Q_{\mathrm{SW}}$ by season (Fig. 9). The greatest differences are over sea ice in summer, although differences over land are also large in spring. Thus a forcing over land in spring operates via feedbacks seen most clearly in sea ice in summer and land in spring. Feedbacks will be more explicitly quantified in Sect. 4.3 when we discuss climate feedback and efficacy.

We can see that the impact on Arctic climate is substantial by looking at the seasonal cycle of the forcing and temperature response (Fig. 10). Interestingly, the magnitude of the temperature response is greatest in the Northern Hemisphere winter. This is further illustrated if we examine maps

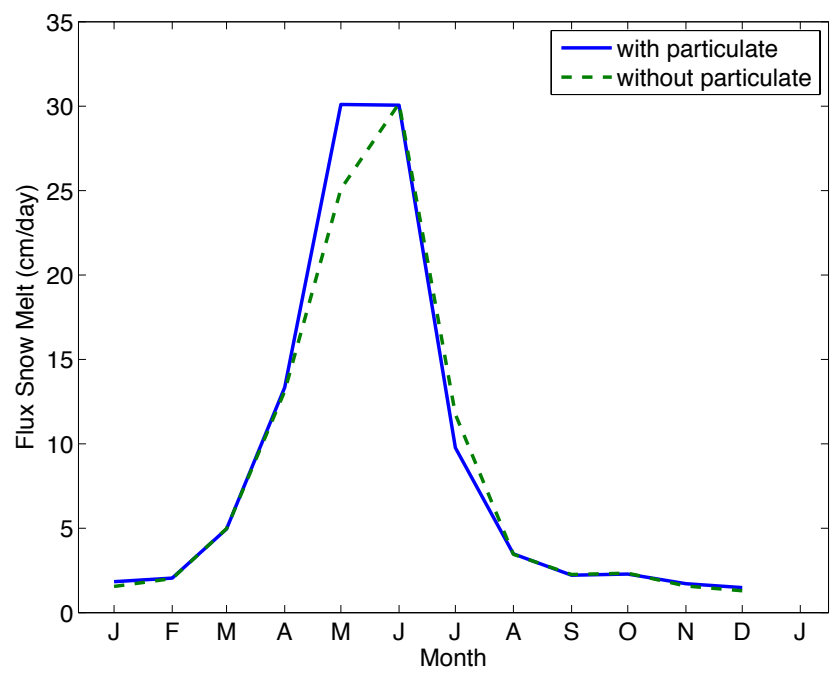

Fig. 7. The seasonal cycle of snow melt rate $\left(\mathrm{cm} \mathrm{day}^{-1}\right)$ North of $60^{\circ} \mathrm{N}$, both with and without the surface particulate impurity forcing applied.

of surface temperature change across four seasons of the year (Fig. 11). In the fall, temperature changes are most notable over sea ice, when thinner sea ice has a great impact on surface temperature; eventually snow on sea ice obscures the effect. The equilibrium radiative response ( $\left.\Delta \mathrm{Q}_{\mathrm{sw}}\right)$ is strongest over sea ice, which insulates ocean-atmosphere heat exchange. The net atmospheric surface flux (net radiative and turbulent) is normally out of the ice in winter, and it is balanced by the conductive heat flux through the ice. Thinner ice causes greater conductive heat flux and a warmer surface. The net atmospheric surface flux is larger, which can only be understood as a response to (not a cause of) the warming.

The spatial pattern of temperature changes in the winter and spring, including some areas of cooling, can be partially explained by atmospheric dynamics. We note in Fig. 12 that the sea level pressure anomaly resembles the Arctic Oscillation (Thompson and Wallace, 1998), or Northern Annular 

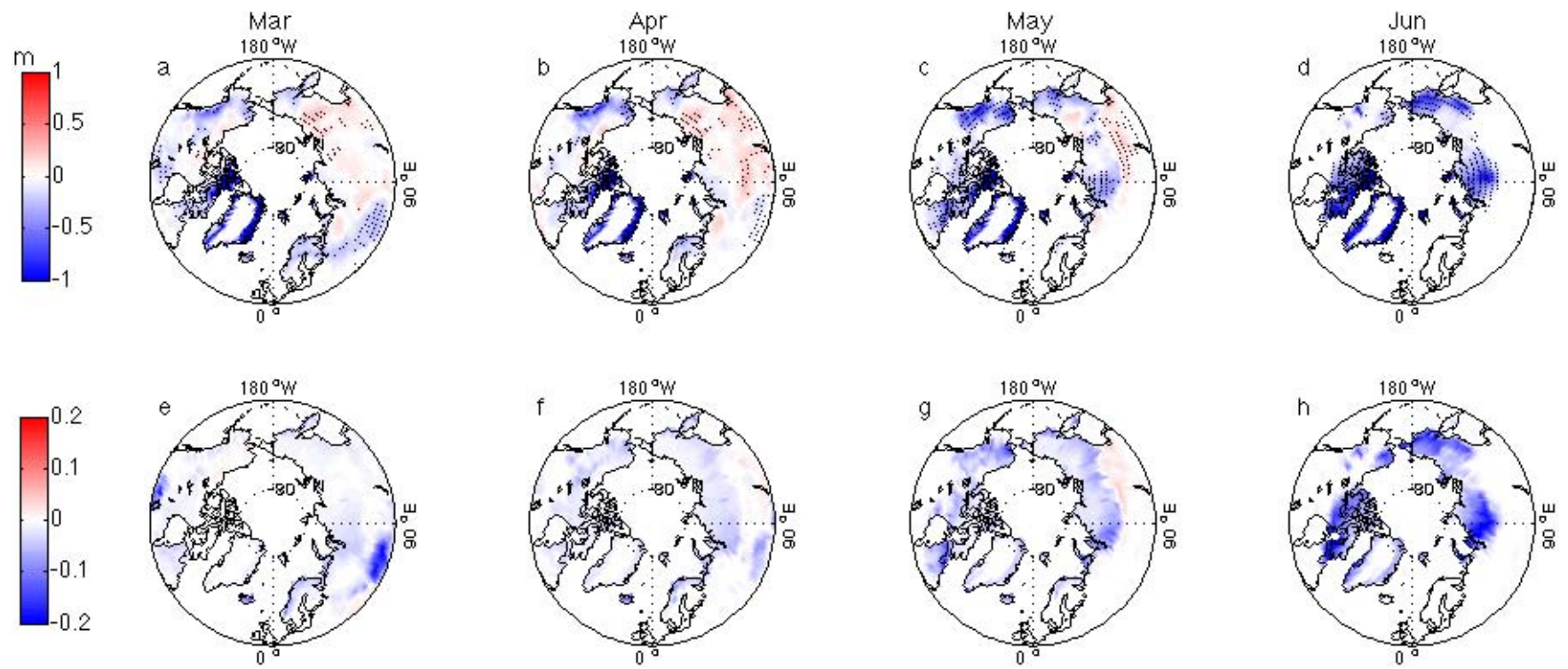

Fig. 8. March-June snow water equivalent thickness difference (a-d) due to light-absorbing particles in snow and sea ice, and the overall surface albedo (decimal 0 to 1 ) difference between runs with and without light-absorbing particles in snow and sea ice. (e-h).
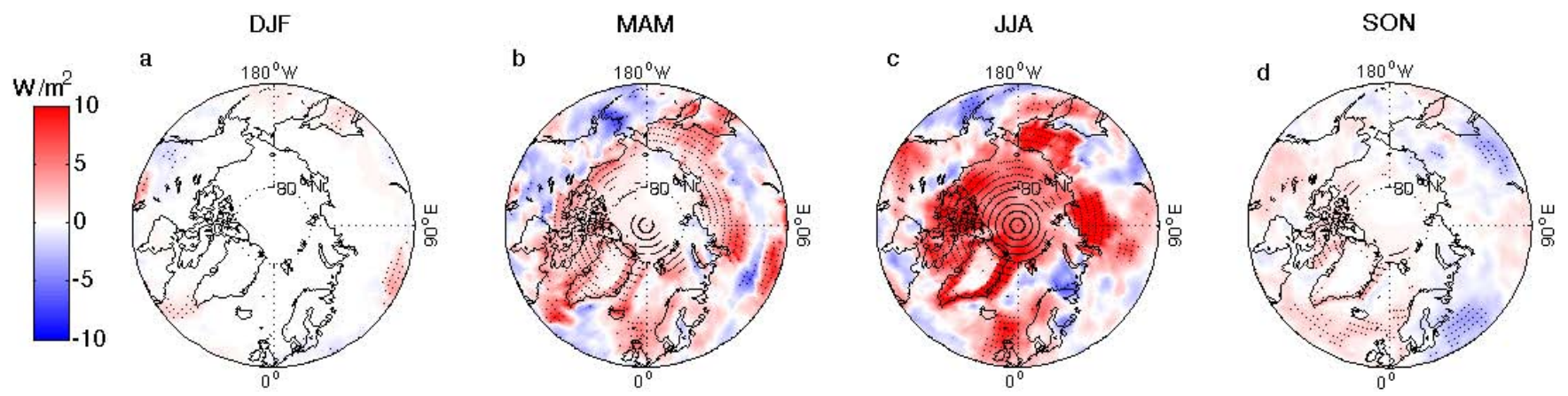

Fig. 9. Net TOA shortwave radiation change $\left(\Delta Q_{\mathrm{SW}}\right)$ due to light-absorbing particles in snow and sea ice, for each season.

Mode, pattern in winter. The strength of the polar vortex is weaker in the presence of the particulate impurity forcing. This corresponds to a zonal wind anomaly that weakens the surface westerlies, causing less warm ocean air to reach into the Eurasian continent and explaining the areas of cooling seen in winter and spring.

We turn our attention to the sea ice response. Figure 13a and $b$ shows the sea ice response at the months of its maximum and minimum yearly extent. The spatial distribution of sea ice thickness anomaly does not correspond to the spatial distribution of deposition flux (Fig. 1) nor the radiative forcing (Fig. 5). Given the snow and ice physics in the various components of CESM1, the particulate forcing prescribed has a substantial impact on Arctic sea ice thickness, with a mean difference of about $-0.25 \mathrm{~m}$ in March and $-0.45 \mathrm{~m}$ in September, for thickness averaged over the area with sea ice concentration greater than $15 \%$ in each integration. Sea ice thickness changes for this and other integrations are found in
Table 2. There is also some reduction in ice extent, particularly in September.

It should be noted, in viewing all of the sea ice thickness plots presented here, that the mean state of sea ice in this model configuration is biased relative to observations. The error in ice extent is most notable in the Labrador Sea, where too much ice is predicted in the year 2000 equilibrium climate. Light absorbing particles only have a climate impact if they are deposited on snow/ice, so an over-estimate of sea ice area will result in an overestimate of the climate response in these regions. However, the climate response in the Labrador Sea is modest in our experiments and contributes little to the global mean estimates.

\subsection{Variations on particulate impurity forcing}

In this section we examine the Arctic climate response to different types of particulate impurity forcing. First we compare the response to 1850 and year 2000 aerosol deposition rates, 

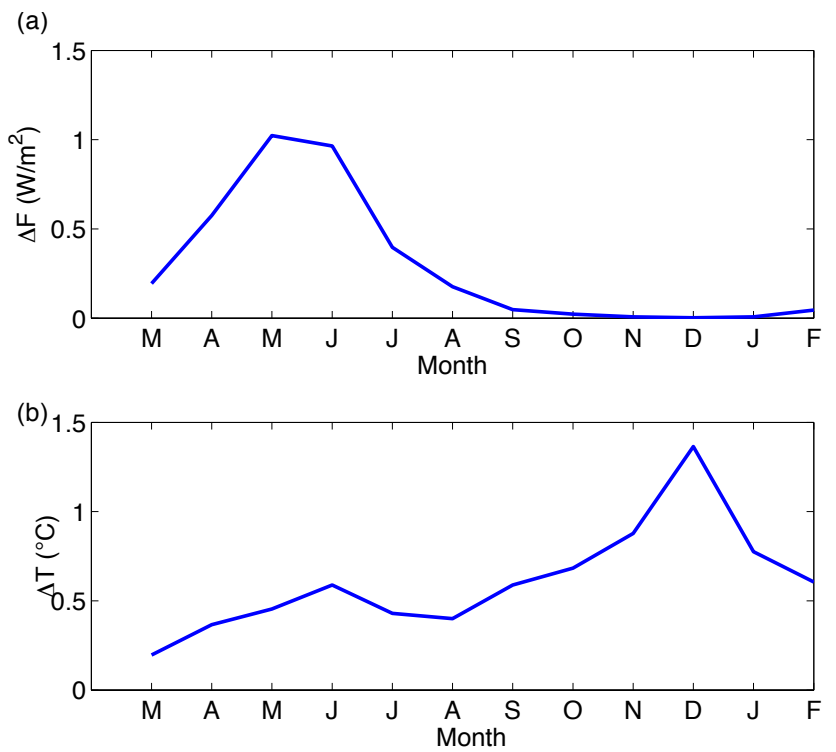

Fig. 10. The seasonal cycles of radiative forcing $(\Delta F)$ and two meter air temperature change $(\Delta T)$ for the area North of $60^{\circ} \mathrm{N}$ due to light-absorbing particles in snow and sea ice.

Table 2. Mean sea ice thickness difference, in meters, for March and September due to light-absorbing particles.

\begin{tabular}{lcc}
\hline & March & September \\
\hline all surface particulate (BC and dust) & -0.25 & -0.45 \\
BC only on sea ice and land & -0.19 & -0.34 \\
dust only on sea ice and land & -0.16 & -0.30 \\
BC and dust on land but not sea ice & -0.21 & -0.34 \\
all BC and dust, 1850 deposition & -0.25 & -0.47 \\
\hline
\end{tabular}

holding constant the level of greenhouse gases. Next we compare the relative importance of dust and BC particles. Finally we compare deposition on terrestrial snow to deposition on sea ice.

\subsubsection{Sensitivity to deposition quantity}

To better understand how the quantity of light-absorbing particles impacts Arctic climate, we compare equilibrium simulations with year 2000 and year 1850 aerosol deposition fluxes. While BC deposition fluxes are higher in the year 2000 case, dust depositions are higher in the 1850 case. Greenhouse gas forcing is kept constant at year 2000 levels for this experiment, so it is only the quantity and distribution of aerosol deposition to the surface that is being tested. The temperature response in the case with 1850-level aerosol deposition is $\Delta T=0.15 \mathrm{~K}$, compared to the deposition-free control run.

The impact on sea ice thickness of deposited particles in the year 1850 and the year 2000 cases, is shown in Fig. 13a$d$. The mean ice thickness change due to either year's partic- ulate impurity forcing is nearly equal: within $0.1 \mathrm{~m}$ of each other. Yet the sea ice response is slightly greater for the 1850 aerosol deposition, when the deposition flux is slightly lower. This has interesting implications for studies that look at changing levels of $\mathrm{BC}$ and other emissions over historical time.

\subsubsection{Relative importance of dust and black carbon}

Next we evaluate the forcing and climate response independently for the two main types of aerosol: dust and $\mathrm{BC}$. We did simulations with only dust and only $\mathrm{BC}$, to compare the equilibrium climate response to these two types of lightabsorbing impurities in snow and sea ice. The global-mean, annual two meter air temperature response is $\Delta T=0.11 \mathrm{~K}$ from $\mathrm{BC}$ alone and $\Delta T=0.12 \mathrm{~K}$ from dust alone (see Table 1 for comparison with other runs).

The climate response, as reflected by the response of sea ice to the surface particulates in these runs is shown in Fig. 14. The mean sea ice thickness difference induced by $\mathrm{BC}$ alone is $-0.19 \mathrm{~m}$ in March and $-0.34 \mathrm{~m}$ in September. For dust only, the sea ice thickness difference is $-0.16 \mathrm{~m}$ in March and $-0.30 \mathrm{~m}$ in September. The dust category alone can account for more than half of the sea ice deficit in the simulation with both $\mathrm{BC}$ and dust when compared to a control run (zero deposition flux). This result is consistent with a result by Lawrence et al. (2012), who found roughly equal contributions to the shortwave absorption in terrestrial snow from $\mathrm{BC}$ and dust.

The distinction between dust and $\mathrm{BC}$ aerosol deposition in the model does not exactly correlate with the distinction between natural and anthropogenic sources. Separating these parts of the forcing is difficult because some dust is generated due to anthropogenic land use changes (Neff et al., 2008), and some BC aerosol is naturally generated by fires (Kim et al., 2005; Warneke et al., 2009). Ideally one might trace the sources of populations of particles in a simulation, but that is not done here.

We also note that the response to light-absorbing impurity forcing is not linear. The non-linearity of the climate response can be seen in the sea ice response: the September year 2000 equilibrium responses due to dust particles and $\mathrm{BC}$ particles at the surface add up to at least $30 \%$ more than the response in sea ice thickness when both are included in the same simulation. In their exploration of the land model response to $\mathrm{BC}$ and dust, Lawrence et al. (2012) note that the sum of the change in shortwave absorption in the snow pack due to $\mathrm{BC}$ and dust separately is greater than shortwave absorption due to both together in the same simulation. This is consistent with the nonlinearity of the climate response that we find. 

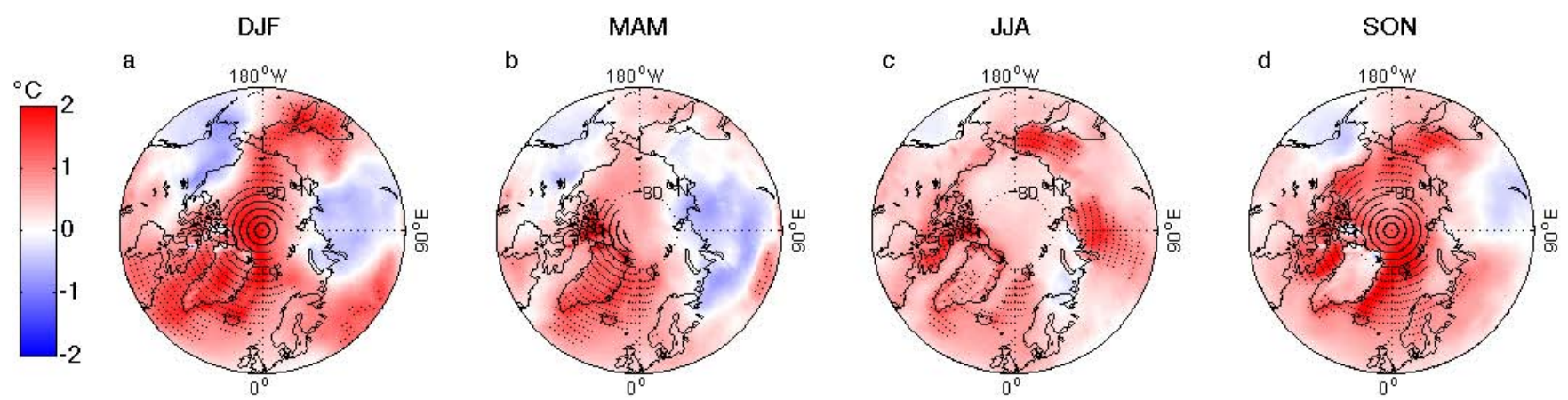

Fig. 11. Two-meter air temperature difference $(\Delta T)$, in ${ }^{\circ} \mathrm{C}$, due to light-absorbing particles in snow and sea ice for each season. Hashes indicate where differences are significant in this and other figures where they appear.
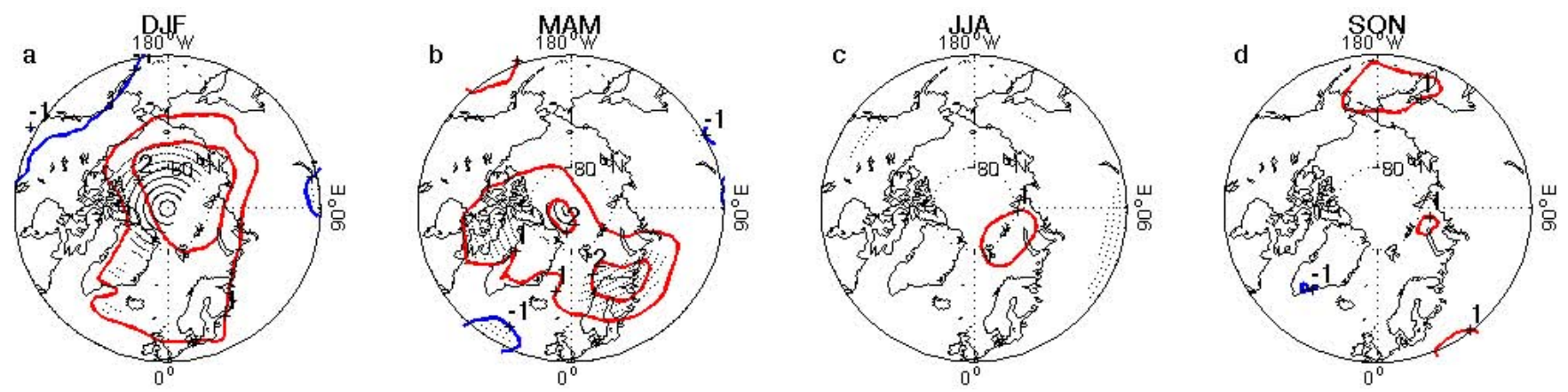

Fig. 12. Sea level pressure difference, in $\mathrm{hPa}$, due to light-absorbing particles in snow and sea ice for each season (positive in red and negative in blue).

\subsubsection{Terrestrial versus marine deposition}

We consider next the relative sensitivity of the model climate to the particulate forcing in terrestrial snow versus that in sea ice (both bare and snow-covered). We separate particles deposited on terrestrial snow from those deposited on the sea ice surface, by doing an experiment with zero deposition fluxes over sea ice, but deposition as usual over land, and compare it to our simulations with particle deposition flux everywhere or with no aerosols deposited anywhere.

Using the integration for which dust and BC are deposited everywhere, and scaling the radiative forcing by land fraction, we find that $56 \%$ of the global mean annual mean radiative forcing is located over land. Additionally, from the integration with particulate impurities only in terrestrial snow, we found evidence that local temperature increases and ice thickness decreases are more strongly driven by the radiative forcing due to particulates in terrestrial snow than the direct forcing resulting from particulates deposited on sea ice directly.

The global mean annual mean temperature anomaly for terrestrial deposition only compared to no aerosol deposition is $\Delta T=0.14 \mathrm{~K}$. The sea ice thickness difference is $-0.21 \mathrm{~m}$ in March and $-0.34 \mathrm{~m}$ in September. Thus, more than half of the decrease in sea ice seen in the simulations with impurities in both terrestrial snow and sea ice, can be explained by the forcing from impurities in terrestrial snow at high latitudes alone. Figure 15 shows the ice thickness difference maps, where sea ice thickness differences are a substantial fraction of those seen in Fig. 13a and b.

In summary, particulates in the high-latitude terrestrial snow contribute a greater portion of the radiative forcing, which then leads to warming that melts more sea ice or retards sea ice growth. The maps of $\Delta Q_{\mathrm{SW}}$ by season suggest that the greater portion of the feedbacks act via the sea ice, even though the largest radiative forcing occurs over land.

Another factor driving the relative effectiveness of terrestrial snow impurities in warming high latitudes is that aerosol deposition generally decreases with latitude because the deep Arctic (and therefore the sea ice) is farther away from industrial and fire-based sources, as well as dust sources. This spatial distribution can be noted in the aerosol deposition flux map for BC (hydrophobic and hydrophilic combined) based on Lamarque et al. (2010), which is shown in Fig. 1.

\subsection{Efficacy and climate feedback}

Equilibrium model runs with $\mathrm{CO}_{2}$ doubled relative to year 2000 levels allow us to compare the surface particulate forcing to that of greenhouse gases. While the magnitude of the 

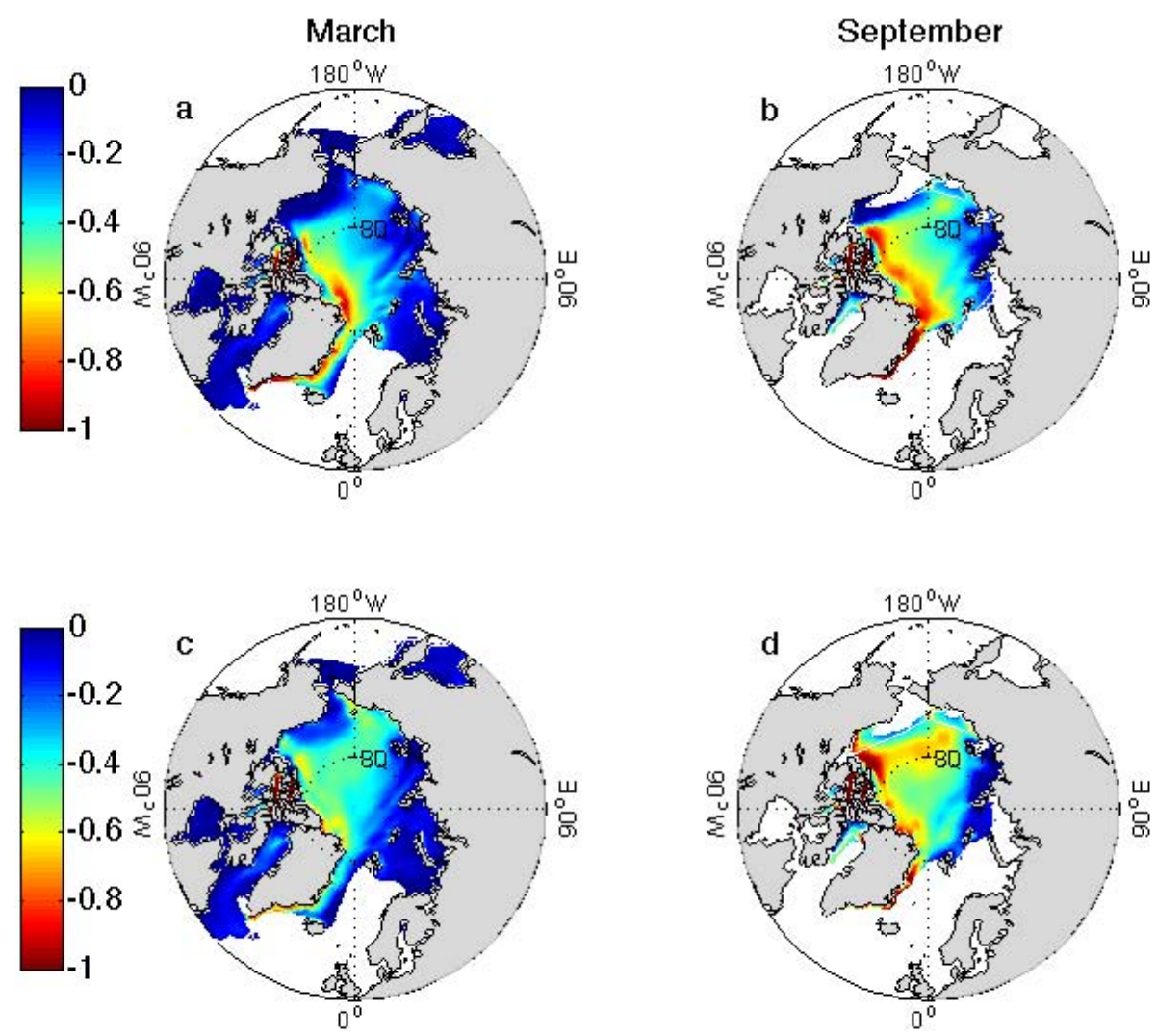

Fig. 13. March and September sea ice thickness change (in meters) due to light-absorbing particles (BC and dust) in snow and sea ice, for March using year 2000 deposition fluxes (a), for September using year 2000 deposition fluxes (b), for March using year 1850 deposition fluxes (c), and for September using year 1850 deposition fluxes (d). Sea ice extent plotted to the contour of $15 \%$ ice area for the aerosol deposition-free control case. Additionally in these and subsequent sea ice plots, the sea ice extent to the $15 \%$ contour for the case in question can be seen as a dashed white line if it differs sufficiently from the impurity-free ice extent.

response from our albedo-influencing light-absorbing particles is much smaller than the impact of doubling $\mathrm{CO}_{2}$ (Fig. 16), the response per unit of forcing is greater.

The efficacy of the forcing, defined by Hansen et al. (2005), compares the climate sensitivity parameter $\Delta T / \Delta F$ for the forcing of interest to that from doubling of $\mathrm{CO}_{2}$ :

Efficacy $=\frac{\left(\frac{\Delta T}{\Delta F}\right)_{\text {other forcing }}}{\left(\frac{\Delta T}{\Delta F}\right)_{\mathrm{CO}_{2}}}$.

The estimate for efficacy depends on how we choose to calculate $\Delta F$, as shown in Hansen et al. (2005). We use $\Delta F$ for surface particulate forcing as described in Sect. 4.1.1 using the values in Table 1.

For doubling of $\mathrm{CO}_{2}$, we use a radiative forcing calculation from Kay et al. (2012) for CESM1 run with CAM4 of $\Delta F_{\mathrm{CO}_{2}}=3.5 \mathrm{~W} \mathrm{~m}^{-2}$. Because this value is based on an experiment doubling $\mathrm{CO}_{2}$ from an 1850 value, we must assume that climate sensitivity does not strongly depend on the mean climate (an assumption we evaluate more in the next section). The temperature difference due to doubling of $\mathrm{CO}_{2}$, from Bitz et al. (2012), is $\Delta T_{\mathrm{CO}_{2}}=3.13 \mathrm{~K}$ for the same slab ocean model configuration used here.
We find a value of 3 for efficacy of all light-absorbing particles in snow and sea ice (BC and dust), and also approximately 3 when we consider $\mathrm{BC}$ or dust only. Thus it seems that a $\mathrm{BC}$ and dust mixture, or just plain $\mathrm{BC}$ are similarly efficacious at affecting the climate. Flanner et al. (2007), using a prior version of CESM, estimated an efficacy of approximately 3 for BC in snow. Hansen et al. (2005), estimated an efficacy for BC in snow and sea ice of $\sim 2.7$ (corrected result in supplemental materials of Hansen et al., 2007) using only prescribed albedo changes, rather than interactive snow and sea ice radiation calculations to determine albedo.

The climate response to a given forcing depends on the extent to which feedbacks amplify or damp the response. We examine the efficacy further by analyzing feedbacks grouped into those that affect shortwave and longwave radiation (see Dickinson, 1986). When the forcing affects the shortwave radiative balance, such as for dust and BC in snow/ice, the shortwave radiative feedback is

$\lambda_{\mathrm{SW}}=\frac{\Delta Q_{\mathrm{SW}}-\Delta F}{\Delta T}=0.90 \mathrm{~W} \mathrm{~m}^{-2} \mathrm{~K}^{-1}$, 

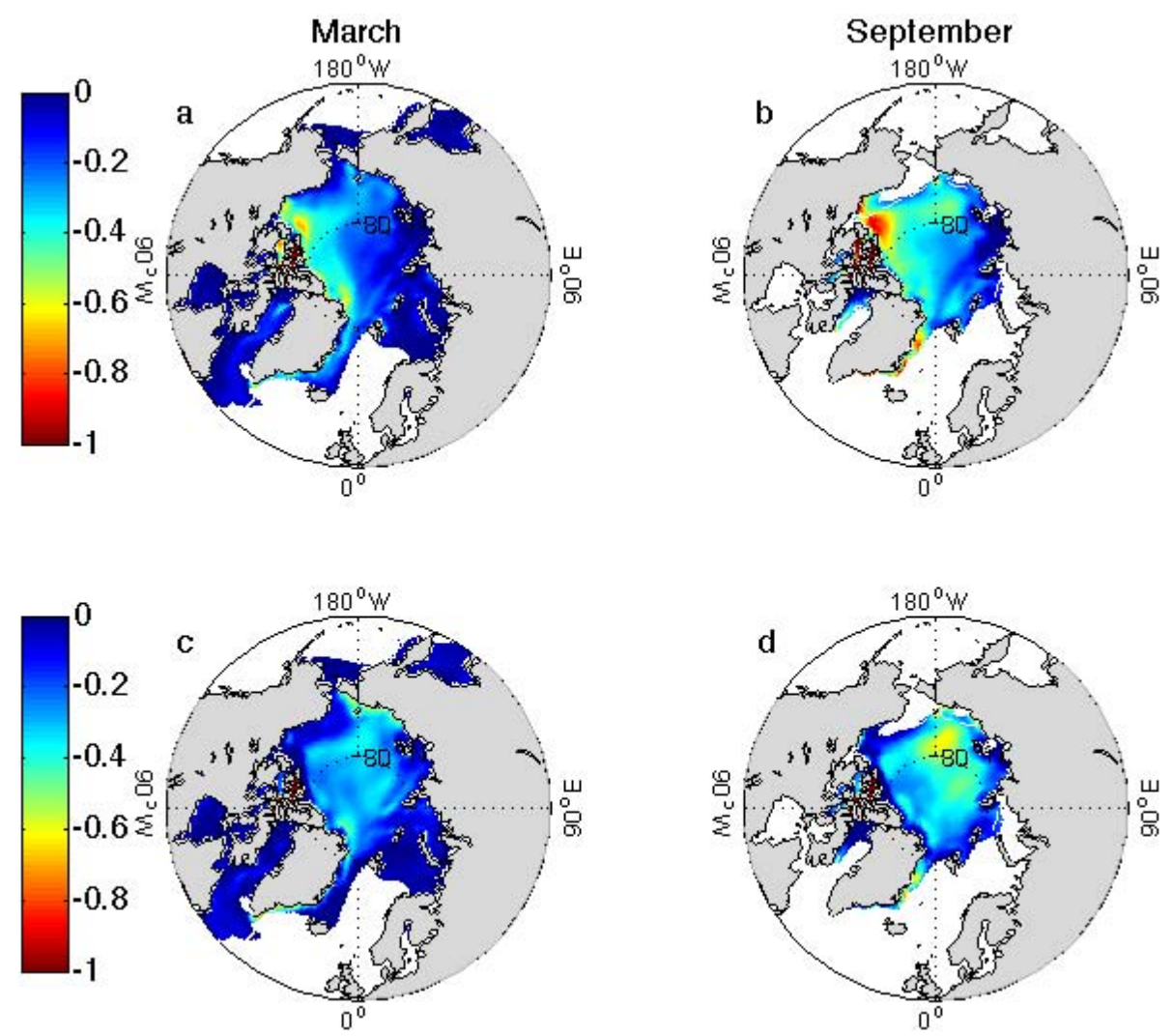

Fig. 14. March and September sea ice thickness change (in meters) due to light-absorbing particles in snow and sea ice, for BC only (a, b) and for dust only $(\mathbf{c}, \mathbf{d})$.
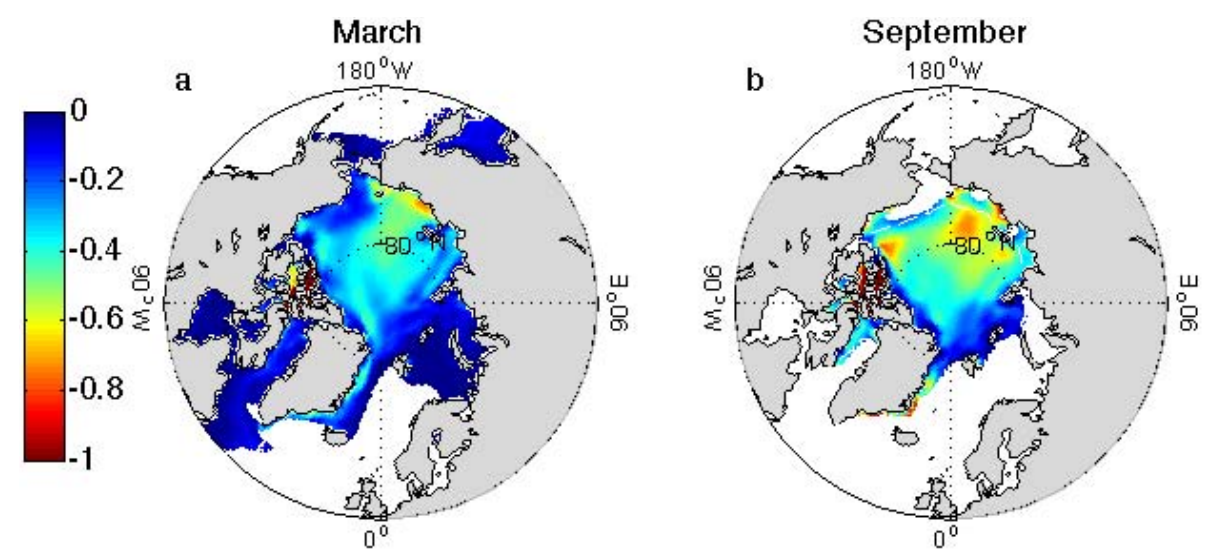

Fig. 15. March and September sea ice thickness change (in meters) due to light-absorbing particles (BC and dust) in terrestrial snow only.

and the longwave radiative feedback is:

$\lambda_{\mathrm{LW}}=-\frac{\Delta Q_{\mathrm{LW}}}{\Delta T}=-1.37 \mathrm{~W} \mathrm{~m}^{-2} \mathrm{~K}^{-1}$

where $\Delta \mathrm{Q}_{\mathrm{LW}}=-\Delta \mathrm{Q}_{\mathrm{SW}}$ at equilibrium. When the forcing affects the longwave radiative balance, such as for greenhouse gas forcing, the quantities $\lambda_{\mathrm{SW}}$ and $\lambda_{\mathrm{LW}}$ are similar but $-\Delta F$ appears in the numerator of the formula for $\lambda_{\mathrm{LW}}$ rather than $\lambda_{\mathrm{SW}}$.
Estimates for $\lambda_{\mathrm{SW}}$ and $\lambda_{\mathrm{LW}}$ for some of our key integrations, along with those for doubled $\mathrm{CO}_{2}$ are in Table 3 . All of the integrations have positive $\lambda_{\mathrm{SW}}$ and negative $\lambda_{\mathrm{LW}}$. But compared to forcing by doubling $\mathrm{CO}_{2}$, the integrations forced with dust and BC have a more positive $\lambda_{\mathrm{SW}}$, indicating stronger positive feedback, and a less negative $\lambda_{\mathrm{LW}}$, indicating less negative feedback. Hence both shortwave and 

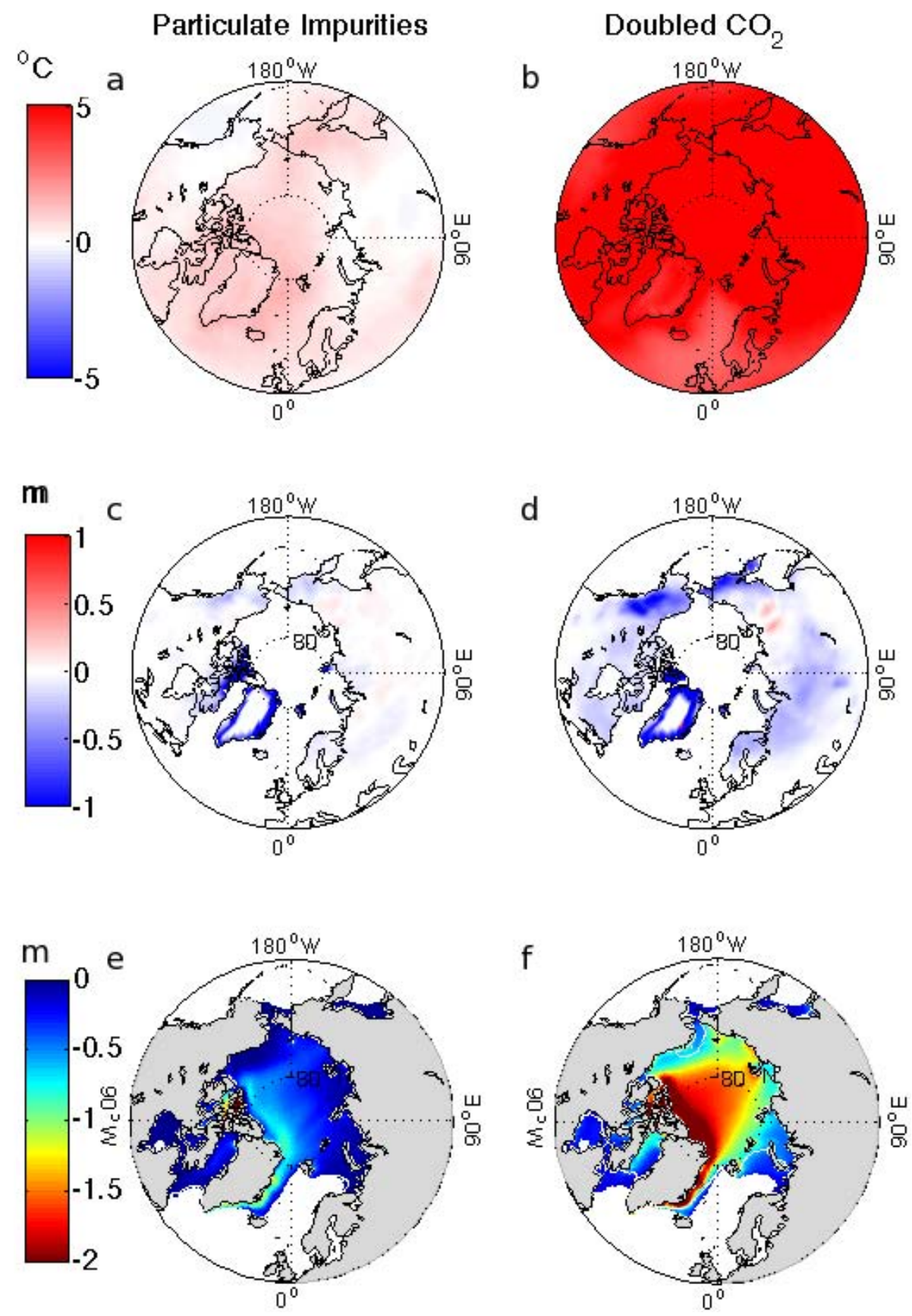

Fig. 16. Annual mean difference in $2 \mathrm{~m}$ reference temperature due to particulate impurities in snow and sea ice (a), and due to doubled carbon dioxide (b). The same to forcings are compared for the response in snow water equivilent $((\mathbf{c})$ and $(\mathbf{d}))$, and for sea ice thickness difference (e) and (f). Values may be saturated in some cases so that the same scale could be used for a given field.

Table 3. Shortwave (SW) and longwave (LW) climate feedback and efficacy.

\begin{tabular}{lccc}
\hline & $\lambda_{\mathrm{SW}}\left(\mathrm{W} \mathrm{m}^{-2}\right) /\left({ }^{\circ} \mathrm{C}\right)$ & $\lambda_{\mathrm{LW}}\left(\mathrm{W} \mathrm{m}^{-2}\right) /\left({ }^{\circ} \mathrm{C}\right)$ & efficacy \\
\hline all surface particulate (BC and dust) & 0.90 & -1.37 & 3 \\
$\mathrm{BC}$ only & 1.23 & -1.78 & 3 \\
dust only & 1.11 & -1.51 & 3 \\
doubled $\mathrm{CO}_{2}$ & 0.79 & -1.9 & 1 \\
\hline
\end{tabular}



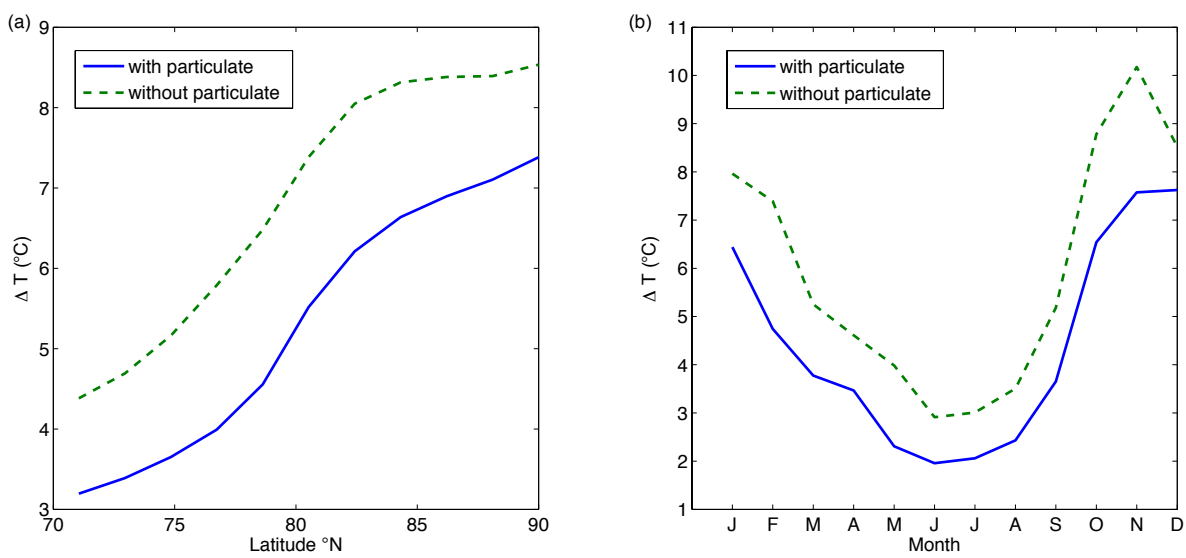

Fig. 17. Two meter air temperature change $(\Delta T)$, in ${ }^{\circ} \mathrm{C}$, due to doubling $\mathrm{CO}_{2}$ in pairs of integrations with and without particulate impurities in snow and sea ice as a function of latitude (a) and month (b) for latitudes North of $70^{\circ} \mathrm{N}$.
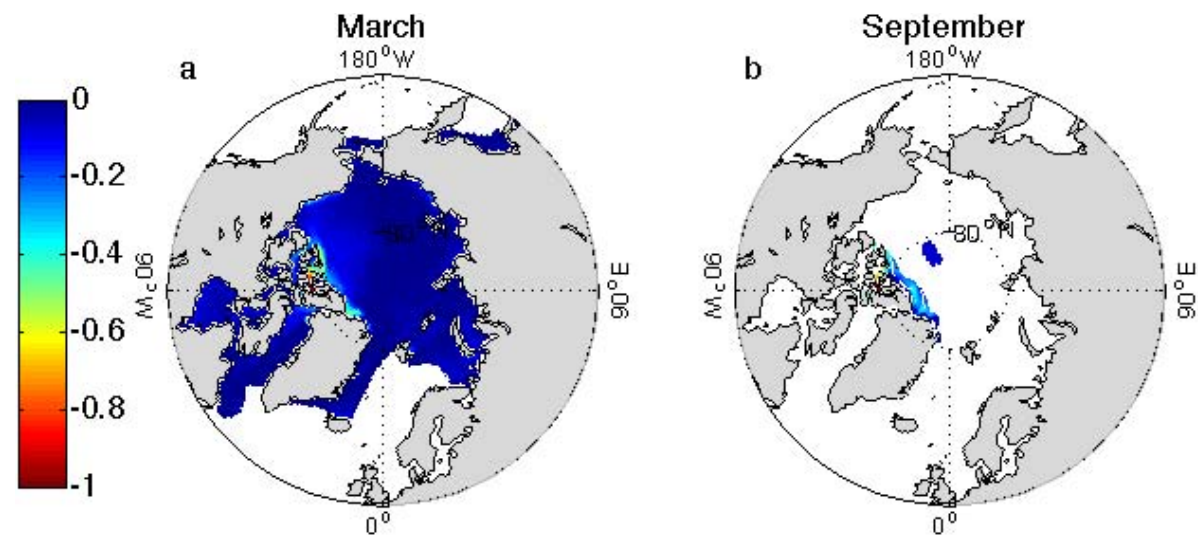

Fig. 18. March and September sea ice thickness change (in meters) due to light-absorbing particles (BC and dust) in snow and sea ice in an integration with $\mathrm{CO}_{2}$ doubled relative to year 2000 .

longwave feedbacks contribute to a larger efficacy for dust and $\mathrm{BC}$ forcing.

In the Arctic compared to the global mean, $\lambda_{\mathrm{SW}}$ and $\lambda_{\mathrm{LW}}$ are relatively more positive (Winton, 2006). Hence it is unsurprising that when the forcing is focused on the Arctic, such as for light-absorbing particles in snow and sea ice, the global mean estimates for $\lambda_{\mathrm{SW}}$ and $\lambda_{\mathrm{LW}}$ are also more positive than they are for doubling $\mathrm{CO}_{2}$. These arguments are further supported by the fact that the surface warming response to dust and $\mathrm{BC}$ is strongly polar amplified (average temperature response North of $70^{\circ} \mathrm{N}$ is $1^{\circ} \mathrm{C}$ ).

\subsubsection{Importance of the simulation control mean state}

The climate change that results from doubling $\mathrm{CO}_{2}$ depends on whether the pair of integrations (control and $2 \times \mathrm{CO}_{2}$ ) have surface impurities in snow and sea ice. As seen in Fig. 17, the temperature change at Northern high latitudes is greater for the pair of integrations that do not include surface impurities.
The importance of sea ice in Arctic climate feedbacks suggests one explanation: with less sea ice from the start when surface impurities are included, doubling $\mathrm{CO}_{2}$ has less impact. Averaging over season for the winter months, we can see a representation of the polar amplification of global warming for each of the alternative model mean states (Fig. 17a). The seasonal cycle in Fig. 17b shows how differences in the mean state are not seasonally uniform.

When we examine the difference in sea ice thickness with and without surface impurities, it is clear that the impact of this forcing in the current climate is much greater than in the simulated climate with doubled $\mathrm{CO}_{2}$ (Fig. 18). This is consistent with the impact of surface impurities in sea ice (and snow on sea ice) found by Holland et al. (2012) when doubling $\mathrm{CO}_{2}$ from an 1850 baseline, instead of our year 2000 baseline.

\subsection{Context}

Some of our results can be compared with prior studies. Flanner et al. (2009) estimated a TOA radiative forcing 
of $0.057 \mathrm{~W} \mathrm{~m}^{-2}$ from $\mathrm{BC}$ darkening of snow in a typical biomass burning year, by scaling the surface forcing by a factor determined from prior modeling. See Table 1 for a full comparison of global mean annual mean temperature difference and radiative forcings for prior studies and this work.

In the more recent version of the model (now CESM1), Lawrence et al. (2012) calculate surface radiative forcing by $\mathrm{BC}$ and dust on terrestrial snow of $0.083 \mathrm{~W} \mathrm{~m}^{-2}$. They also note the impact in springtime (March-April-May), when the forcing is greatest is $0.17 \mathrm{~W} \mathrm{~m}^{-2}$, averaging only over the areas where snow is present. While these estimates are based on updated model parameterizations from those in Flanner et al. (2009), they are for terrestrial snow only, and do not include sea ice.

Holland et al. (2012) find that the additional shortwave energy absorbed at the surface averaged over the Arctic basin from $\mathrm{BC}$ and dust particles on and in sea ice always remains below $1 \mathrm{~W} \mathrm{~m}^{-2}$ in their 1850 equilibrium simulation. They find that the importance of the forcing by light-absorbing particulate impurities decreases in a doubled $\mathrm{CO}_{2}$ experiment, as the sea ice area is reduced. This too is consistent with our results, although Holland et al. (2012) do not take into account the forcing from similar particles on terrestrial snow.

We have examined the equilibrium sensitivity of CESM1 to simulated deposition of black carbon and dust, but the actual magnitude of the forcing in the climate system may differ from our simulated values. Further constraints could be placed on this forcing and the climate response with additional modeling studies and by more extensive testing of the model against measurements. Interactively computing aerosol transport and deposition with resultant feedbacks in a fully-coupled simulation would test the model variability in response to all sources of light-absorbing aerosol.

Additional field measurements are also needed to evaluate model surface impurity concentrations. While we have shown that CESM is not grossly in error in its representation of BC concentrations, modeled snow and ice dust concentrations have not been tested against observations. Further, the possible role of light absorbing organics is currently completely omitted from these studies.

\section{Conclusions}

We isolate the model climate response to light-absorbing particulate impurities in snow and sea ice in equilibrium sensitivity experiments with CESM1. We find a modest surface albedo forcing can have a large regional climate impact due to feedbacks in the system, particularly the sea ice albedo feedback.

Darkening of terrestrial snow, sea ice, and snow on sea ice by dust and $\mathrm{BC}$ results in increased air temperatures and a subsequent reduction in sea ice thickness. Particularly as pertains to the sea ice anomaly, the forcing operates more through feedbacks driven by the surface warming than through direct localized increases in shortwave absorption.

The particulate impurity forcing is greatest over land and in the spring. The shortwave radiative response is greatest over sea ice and in the summer, reflecting the role of feedbacks involving sea ice. The temperature response is greatest at high Northern latitudes in the winter.

We have computed an estimate of efficacy of $\sim 3$ for BC (as well as BC and dust together) as forcing agents in snow and sea ice. The efficacy results from about equal contributions from more positive shortwave radiative feedbacks and less negative longwave radiative feedbacks.

Given constant levels of greenhouse gases, a level of BC and dust deposition that corresponds to the year 1850 is quite similar to the response with year 2000 level aerosol deposition. Given the depositions we prescribed for year 2000, dust is as large of a contributor as BC. We find that forcing by snow and sea ice impurities has a larger climate impact in a cooler climate than in a doubled $\mathrm{CO}_{2}$ climate, because warming by greenhouse gases reduces snow and ice cover, thereby lessening the potential for forcing by impurities in snow and sea ice.

Taken together our results suggest that $\mathrm{BC}$ and dust in snow and sea ice may have had a substantial impact on Arctic climate, but compensating effects have tended to make the influence fairly even since pre-industrial times. The climatic impacts are likely to diminish in the future.

Acknowledgements. The authors gratefully acknowledge the support of the National Science Foundation through grant ARC1049002 and through the Extreme Science and Engineering Discovery Environment (XSEDE) computing resources provided by the Texas Advanced Computing Center under grant number [TG-ATM090059]. Mark Flanner helped us to better understand the SNICAR model and the quantities used therein. Steve Warren provided helpful comments and insight into processes involving impurities in snow.

Edited by: M. K. Dubey

\section{References}

Bitz, C. M., Shell, K. M., Gent, P. R., Bailey, D., Danabasoglu, G., Armour, K. C., Holland, M. M., and Kiehl, J. T.: Climate Sensitivity of the Community Climate System Model Version 4, J. Climate, 25, 3053-3070, doi:10.1175/JCLI-D-11-00290.1, 2012.

Bond, T. and Bergstrom, R.: Light absorption by carbonaceous particles: An investigative review, Aerosol Sci. Technol., 40, 27-67, 2006.

Bond, T. C., Streets, D. G., Yarber, K. F., Nelson, S. M., Woo, J.-H., and Klimont, Z.: A technology-based global inventory of black and organic carbon emissions from combustion, J. Geophys. Res.-Atmos., 109, D14203, doi:10.1029/2003JD003697, 2004.

Bond, T. C., Habib, G., and Bergstrom, R. W.: Limitations in the enhancement of visible light absorption due to mixing state, J. Geo- 
phys. Res.-Atmos., 111, D20211, doi:10.1029/2006JD007315, 2006.

Briegleb, B. and Light, B.: A Delta-Eddington Multiple Scattering Parameterization for Solar Radiation in the Sea Ice Component of the Community Climate System Model, NCAR Technical Note, 2007.

Chang, H. and Charalampopoulos, T.: Determination of the Wavelength Dependence of Refractive-Indexes of Flame Soot, Proc. Roy. Soc. Ldn. - Math. Phys. Eng. Sci., 430, 577-591, 1990.

Clarke, A. and Noone, K.: Soot in the Arctic Snowpack - A Cause for Perturbations in Radiative-Transfer, Atmos. Environ., 19, 2045-2053, 1985.

Conway, H., Gades, A., and Raymond, C. F.: Albedo of dirty snow during conditions of melt, Water Resour. Res., 32, 1713-1718, 1996.

Dickinson, R.: How will future climate change?, in: The Greenhouse Effect, Climate Change, and Ecosystems, edited by: Bolin, B., Doos, B., Jaeger, J., and Warrick, R., SCOPE Rep. 29, 206270, J. Wiley, New York, USA, 1986.

Doherty, S. J., Warren, S. G., Grenfell, T. C., Clarke, A. D., and Brandt, R. E.: Light-absorbing impurities in Arctic snow, Atmos. Chem. Phys., 10, 11647-11680, doi:10.5194/acp-1011647-2010, 2010.

Flanner, M. G. and Zender, C. S.: Snowpack radiative heating: Influence on Tibetan Plateau climate, Geophys. Res. Lett., 32, L06501, doi:10.1029/2004GL022076, 2005.

Flanner, M. G. and Zender, C. S.: Linking snowpack microphysics and albedo evolution, J. Geophys. Res.-Atmos., 111, D12208, doi:10.1029/2005JD006834, 2006.

Flanner, M. G., Zender, C. S., Randerson, J. T., and Rasch, P. J.: Present-day climate forcing and response from black carbon in snow, J. Geophys. Res.-Atmos., 112, D11202, doi:10.1029/2006JD008003, 2007.

Flanner, M. G., Zender, C. S., Hess, P. G., Mahowald, N. M., Painter, T. H., Ramanathan, V., and Rasch, P. J.: Springtime warming and reduced snow cover from carbonaceous particles, Atmos. Chem. Phys., 9, 2481-2497, doi:10.5194/acp-9-24812009, 2009.

Flanner, M. G., Liu, X., Zhou, C., and Penner, J. E.: Enhanced solar energy absorption by internally-mixed black carbon in snow grains, Atmos. Chem. Phys., 12, 4699-4721, doi:10.5194/acp12-4699-2012, 2012.

Hansen, J. and Nazarenko, L.: Soot climate forcing via snow and ice albedos, P. Natl. Acad. Sci. USA, 101, 423-428, 2004.

Hansen, J., Sato, M., Ruedy, R., Nazarenko, L., Lacis, A., Schmidt, G. A., Russell, G., Aleinov, I., Bauer, M., Bauer, S., Bell, N., Cairns, B., Canuto, V., Chandler, M., Cheng, Y., Del Genio, A., Faluvegi, G., Fleming, E., Friend, A., Hall, T., Jackman, C., Kelley, M., Kiang, N., Koch, D., Lean, J., Lerner, J., Lo, K., Menon, S., Miller, R., Minnis, P., Novakov, T., Oinas, V., Perlwitz, J., Perlwitz, J., Rind, D., Romanou, A., Shindell, D., Stone, P., Sun, S., Tausnev, N., Thresher, D., Wielicki, B., Wong, T., Yao, M., and Zhang, S.: Efficacy of climate forcings, J. Geophys. Res., 110, D18104, doi:10.1029/2005JD005776, 2005.

Hansen, J., Sato, M., Ruedy, R., Kharecha, P., Lacis, A., Miller, R., Nazarenko, L., Lo, K., Schmidt, G., Russell, G., Aleinov, I., Bauer, S., Baum, E., Cairns, B., Canuto, V., Chandler, M., Cheng, Y., Cohen, A., Del Genio, A., Faluvegi, G., Fleming, E., Friend, A., Hall, T., Jackman, C., Jonas, J., Kelley, M., Kiang, N.,
Koch, D., Labow, G., Lerner, J., Menon, S., Novakov, T., Oinas, V., Perlwitz, J., Perlwitz, J., Rind, D., Romanou, A., Schmunk, R., Shindell, D., Stone, P., Sun, S., Streets, D., Tausnev, N., Thresher, D., Unger, N., Yao, M., and Zhang, S.: Climate simulations for 1880-2003 with GISS modelE, Clim. Dynam., 29, 661-696, 2007.

Hegg, D. A., Warren, S. G., Grenfell, T. C., Doherty, S. J., Larson, T. V., and Clarke, A. D.: Source Attribution of Black Carbon in Arctic Snow, Environ. Sci. Technol., 43, 4016-4021, 2009.

Hegg, Dean A., Warren, Stephen G., Grenfell, Thomas C., Sarah J Doherty, and Clarke, Antony D.: Sources of light-absorbing aerosol in arctic snow and their seasonal variation, Atmos. Chem. Phys., 10, 10923-10938, doi:10.5194/acp-10-10923-2010, 2010.

Holland, M. M., Bailey, D. A., Briegleb, B. P., Light, B., and Hunke, E.: Improved sea ice shortwave radiation physics in CCSM4: The impact of melt ponds and aerosols on Arctic sea ice, J. Climate, doi:10.1175/JCLI-D-11-00078.1, 2012.

Hunke, E. C. and Lipscomb, W. H.: CICE: the Los Alamos Sea Ice Model, Documentation and Software, Version 4.0., Tech. Rep. LA-CC-06-012, Los Alamos National Laboratory, 2008.

IPCC: Climate Change 2007: The Physical Science Basis. Contribution of Working Group I to the Fourth Assessment Report of the Intergovernmental Panel on Climate Change, vol. 446, Cambridge University Press, 2007.

Jacobson, M.: Climate response of fossil fuel and biofuel soot, accounting for soot's feedback to snow and sea ice albedo and emissivity, J. Geophys. Res.-Atmos., 109, D21201, doi:10.1029/2004JD004945, 2004.

Jahn, A., Sterling, K., Holland, M. M., Kay, J. E., Maslanik, J. A., Bitz, C. M., Bailey, D. A., Stroeve, J., Hunke, E. C., Lipscomb, W. H., and Pollak, D. A.: Late-Twentieth-Century Simulation of Arctic Sea Ice and Ocean Properties in the CCSM4, J. Climate, 25, 1431-1452, doi:10.1175/JCLI-D-11-00201.1, 2012.

Kay, J. E., Holland, M. M., Bitz, C. M., Blanchard-Wrigglesworth, E., Gettelman, A., Conley, A., and Bailey, D.: The influence of local feedbacks and northward heat transport on the equilibrium Arctic climate response to increased greenhouse gas forcing, 25, 5433-5450, doi:10.1175/JCLI-D-11-00622.1, 2012.

Kim, Y., Hatsushika, H., Muskett, R. R., and Yamazaki, K.: Possible effect of boreal wildfire soot on Arctic sea ice and Alaska glaciers, Atmos. Environ., 39, 3513-3520, 2005.

Lamarque, J.-F., Bond, T. C., Eyring, V., Granier, C., Heil, A., Klimont, Z., Lee, D., Liousse, C., Mieville, A., Owen, B., Schultz, M. G., Shindell, D., Smith, S. J., Stehfest, E., Van Aardenne, J., Cooper, O. R., Kainuma, M., Mahowald, N., McConnell, J. R., Naik, V., Riahi, K., and van Vuuren, D. P.: Historical (1850-2000) gridded anthropogenic and biomass burning emissions of reactive gases and aerosols: methodology and application, Atmos. Chem. Phys., 10, 7017-7039, doi:10.5194/acp10-7017-2010, 2010.

Law, K. S. and Stohl, A.: Arctic air pollution: Origins and impacts, Science, 315, 1537-1540, 2007.

Lawrence, D. M. and Slater, A. G.: The contribution of snow condition trends to future ground climate, Clim. Dynam., 34, 969-981, 2010.

Lawrence, D. M., Oleson, K. W., Flanner, M. G., Thornton, P. E., Swenson, S. C., Lawrence, P. J., Zeng, X., Yang, Z.-L., Levis, S., Sakaguchi, K., Bonan, G. B., and Slater, A. G.: Parameterization improvements and functional and structural advances in Version 
4 of the Community Land Model, Journal of Advances in Modeling Earth Systems, 30, 3001, doi:10.1029/2011MS000045, 2011.

Lawrence, D. M., Oleson, K. W., Flanner, M. G., Fletcher, C. G., Lawrence, P. J., Levis, S., Swenson, S. C., and Bonan, G. B.: The CCSM4 land simulation, 1850-2005: Assessment of surface climate and new capabilities, J. Climate, doi:10.1175/JCLI-D11-00103.1, in press, 2012.

Mahowald, N. M., Muhs, D. R., Levis, S., Rasch, P. J., Yoshioka, M., Zender, C. S., and Luo, C.: Change in atmospheric mineral aerosols in response to climate: Last glacial period, preindustrial, modern, and doubled carbon dioxide climates, J. Geophys. Res.Atmos., 111, D10202, doi:10.1029/2005JD006653, 2006.

Mahowald, N. M., Kloster, S., Engelstaedter, S., Moore, J. K., Mukhopadhyay, S., McConnell, J. R., Albani, S., Doney, S. C., Bhattacharya, A., Curran, M. A. J., Flanner, M. G., Hoffman, F. M., Lawrence, D. M., Lindsay, K., Mayewski, P. A., Neff, J., Rothenberg, D., Thomas, E., Thornton, P. E., and Zender, C. S.: Observed 20th century desert dust variability: impact on climate and biogeochemistry, Atmos. Chem. Phys., 10, 10875-10893, doi:10.5194/acp-10-10875-2010, 2010.

McConnell, J. R., Edwards, R., Kok, G. L., Flanner, M. G., Zender, C.S., Saltzman, E. S., Banta, J. R., Pasteris, D. R., Carter, M. M., and Kahl, J. D. W.: 20th-Century Industrial Black Carbon Emissions Altered Arctic Climate Forcing, Science, 317, 1381, 2007.

McConnell, J. R.: New directions: historical black carbon and other ice core aerosol records in the Arctic for GCM evaluation, Atmos. Environ., 44, 2665-2666, 2010.

Neff, J. C., Ballantyne, A. P., Farmer, G. L., Mahowald, N. M., Conroy, J. L., Landry, C. C., Overpeck, J. T., Painter, T. H., Lawrence, C. R., and Reynolds, R. L.: Increasing eolian dust deposition in the western United States linked to human activity, Nature Geosci., 1, 189-195, 2008.

Niu, G.-Y. and Yang, Z.-L.: An observation-based formulation of snow cover fraction and its evaluation over large North American river basins, J. Geophys. Res.-Atmos., 112, D21101, doi:10.1029/2007JD008674, 2007.

Patterson, E.: Optical-properties of the Crustal Aerosol - Relation to Chemical and Physical Characteristics, J. Geophys. Res.-Ocean. Atmos., 86, 3236-3246, 1981.

Quinn, P. K., Shaw, G., Andrews, E., Dutton, E. G., Ruoho-Airola, T., and Gong, S. L.: Arctic haze: current trends and knowledge gaps, Tellus B, 59, 99-114, 2007.

Shindell, D. T., Chin, M., Dentener, F., Doherty, R. M., Faluvegi, G., Fiore, A. M., Hess, P., Koch, D. M., MacKenzie, I. A., Sanderson, M. G., Schultz, M. G., Schulz, M., Stevenson, D. S., Teich, H., Textor, C., Wild, O., Bergmann, D. J., Bey, I., Bian, H., Cuvelier, C., Duncan, B. N., Folberth, G., Horowitz, L. W., Jonson, J., Kaminski, J. W., Marmer, E., Park, R., Pringle, K. J., Schroeder, S., Szopa, S., Takemura, T., Zeng, G., Keating, T. J., and Zuber, A.: A multi-model assessment of pollution transport to the Arctic, Atmos. Chem. Phys., 8, 5353-5372, doi:10.5194/acp-85353-2008, 2008.
Sokolik, I. N. and Toon, O. B.: Incorporation of mineralogical composition into models of the radiative properties of mineral aerosol from UV to IR wavelengths, J. Geophys. Res., 104, 9423-9444, 1999.

Stohl, A.: Characteristics of atmospheric transport into the Arctic troposphere, J. Geophys. Res.-Atmos., 111, D11306, doi:10.1029/2005JD006888, 2006.

Thompson, D. W. J. and Wallace, J. M.: The Arctic Oscillation signature in the wintertime geopotential height and temperature fields, Geophys. Res. Lett., 25, 1297-1300, 1998.

Wang, A. and Zeng, X.: Improving the treatment of the vertical snow burial fraction over short vegetation in the NCAR CLM3, Adv. Atmos. Sci., 26, 877-886, 2009.

Warneke, C., Bahreini, R., Brioude, J., Brock, C. A., de Gouw, J. A., Fahey, D. W., Froyd, K. D., Holloway, J. S., Middlebrook, A., Miller, L., Montzka, S., Murphy, D. M., Peischl, J., Ryerson, T. B., Schwarz, J. P., Spackman, J. R., and Veres, P.: Biomass burning in Siberia and Kazakhstan as an important source for haze over the Alaskan Arctic in April 2008, Geophys. Res. Lett., 36, L02813, doi:10.1029/2008GL036194, 2009.

Warren, S. G. and Clarke, A. D.: Soot from Arctic Haze: Radiative Effects on the Arctic Snowpack, in: Snow Watch '85, edited by: Kukla, G., Barry, R. G., Hecht, A., and Wiesnet, D., 73-77, Glaciological Data, Report GD-18, 1986.

Warren, S. G. and Clarke, A. D.: Soot in the atmospheric and snow surface of Antarctica, J. Geophys. Res., 95, 1811-1816, 1990.

Warren, S. and Wiscombe, W.: A model for the spectral albedo of snow .2. Snow containing atmospheric aerosols, J. Atmos. Sci., 37, 2734-2745, 1980.

Warren, S. G. and Wiscombe, W. J.: Dirty snow after nuclear war, Nature, 313, 467-470, 1985.

Winton, M.: Amplified Arctic climate change: What does surface albedo feedback have to do with it?, Geophys. Res. Lett., 33, L03701, doi:10.1029/2005GL025244, 2006.

Wiscombe, W. and Warren, S.: A model for the spectral albedo of snow .1. Pure snow, J. Atmos. Sci., 37, 2712-2733, 1980.

Xu, B., Yao, T., Liu, X., and Wang, N.: Elemental and organic carbon measurements with a two-step heating-gas chromatography system in snow samples from the Tibetan Plateau, Ann. Glaciol., 43, 257-262, 2006.

Zender, C., Bian, H., and Newman, D.: Mineral Dust Entrainment and Deposition (DEAD) model: Description and 1990s dust climatology, J. Geophys. Res.-Atmos., 108, D144416, doi:10.1029/2002JD002775, 2003. 